\title{
Recent advances in polymer/layered silicate nanocomposites: an overview from science to technology
}

\section{Okamoto*}

\begin{abstract}
Polymer/layered silicate nanocomposites (PLSNCs) offer remarkably improved mechanical and other properties with low inorganic filler loading. The major development in this field has been carried out over the last one and a half decades. However, the authors are far from the goal in terms of understanding the mechanisms of the enhancement effect in the nanocomposites. Continued progress in nanoscale controlling and an improved understanding of the physicochemical phenomena at the nanometre scale have contributed to the rapid development of novel PLSNCs. The present paper describes recent advances in PLSNCs with the primary focus on these advances from basic science to technology.
\end{abstract}

Keywords: Nanocomposite, Layered silicate

\section{Introduction}

A decade of research has shown that nanostructured materials have the potential to significantly impact growth at every level of the world economy in the twenty-first century. This new class of materials is now being introduced in structural applications, such as gas barrier film, flame retardant product and other load bearing applications (see Table 1). ${ }^{1}$

Of particular interest is recently developed nanocomposites consisting of a polymer and layered silicate (LS), because they often exhibit remarkably improved mechanical and other properties ${ }^{2}$ when compared with pure polymer or conventional composites (both micro and macrocomposites). A primary progress in polymer/ layered silicate nanocomposites (PLSNCs), a nylon 6/LS hybrid $^{3}$ reported by Toyota Central Research \& Development Co. Inc. (TCRD), was successfully prepared by in situ polymerisation of $\varepsilon$-caprolactam in a dispersion of montomorrillonite (MMT). The silicate can be dispersed in liquid monomer or a solution of monomer. It has also been possible to melt and mix polymers with layered silicates, avoiding the use of organic solvents. The latter method permits the use of conventional processing techniques such as injection moulding and extrusion.

Continued progress in nanoscale controlling and an improved understanding of the physicochemical phenomena at the nanometre scale have contributed to the rapid development of novel PLSNCs. The present paper describes current research on PLSNCs with the primary

Advanced Polymeric Materials Engineering, Graduate School of Engineering, Toyota Technological Institute, 2-12-1 Hisakata, Tempaku, Nagoya 468 8511, Japan

*Corresponding author, email okamoto@toyota-ti.ac.jp focus on recent advances from basic science to technology.

\section{Historical point of view}

Earlier attempts of preparing polymer/LS composites are found in almost half a century old patent literatures. ${ }^{4,5} \mathrm{In}$ such cases, incorporation of $40-50 \mathrm{wt}-\%$ clay mineral (bentonite, hectorite, etc.) into a polymer was attempted but ended up with unsatisfactory results: the maximal modulus enhancement was only $\sim 200 \%$, although the clay loading was as much as $50 \mathrm{wt}-\%$. The failure was obvious, because they failed to achieve good dispersion of clay particles in the matrix, in which silicate minerals existed as agglomerated tactoids. Such a poor dispersion of the silicate particles could improve the material rigidity, but certainly sacrificing the strength, the elongation at break and the toughness of the materials. ${ }^{4,5}$

A major reason for this impossibility of improving the tactoids dispersion into well dispersed-exfoliated monolayers of the silicate is obviously due to the intrinsic incompatibility of hydrophilic layered silicates with hydrophobic engineering plastics. One attempt at circumventing this difficulty was made by Unitika Ltd. $^{6}$ about 30 years ago in preparing nylon 6/LS composites (not nanocomposites) via in situ polymerisation of $\varepsilon$-caprolactam with MMT, but the results turned out to be not very good.

The first major breakthrough of the problem was brought about in 1987, when Fukushima and Inagaki of TCRD, via their detailed study on polymer/LS composites, persuasively demonstrated that lipophilisation by replacing inorganic cations in galleries of the native clay with alkylammonium surfactant successfully made them compatible with hydrophobic polymer matrixes. ${ }^{7}$ The modified clay was thus called lipophilised clay, organophillic clay or simply organoclay. Furthermore, 
they found that the lipophilisation enabled to expand silicate galleries and exfoliate the silicate layers into single layers of a nanometre thickness.

Six years later, in 1993, Usuki, Fukushima and their colleagues of TCRD successfully prepared, for the first time, and exfoliated nylon 6/MMT hybrid via in situ polymerisation of $\varepsilon$-caprolactam, in which alkylammonium modified MMT was thoroughly dispersed in advance. $^{3,8}$

Apart from this, the intercalation of small molecules into silicate galleries has been found by researchers when studying Mayan archeological sites. ${ }^{9}$ Maya blue was used in Mesoamerica and colonial Mexico as late as the twentieth century. Maya blue colour is resistant to diluted mineral acids, alkalis, moderate heat and even biocorrosion. This blue colour contains clay (mainly MMT clay and palygorskite $\left(\mathrm{Mg}_{5}(\mathrm{Si}, \mathrm{Al})_{8} \mathrm{O}_{20}(\mathrm{OH})_{2} 8 \mathrm{H}_{2} \mathrm{O}\right)$ (see Table 2)) and indigo molecules $\left(\mathrm{C}_{16} \mathrm{H}_{10} \mathrm{~N}_{2} \mathrm{O}_{2}\right)$. Intercalation of indigo molecules into MMT galleries and/or encapsulation in the pores of palygorskite might explain the corrosion resistance in the extreme condition of the rain forest. Up to now, Maya blue paint has been understood as an origin of the intercalation and recognised as an ancient nanostructured materials (see Fig. 1).

\section{Structure of layered silicates and its modification}

The commonly clays used for the preparation of PLSNCs belong to the same general family of phyllosilicates. Their crystal structure consists of layers made up of two silica tetrahedral fused to an edge shared octahedral sheet of either aluminium or magnesium hydroxide. The layer thickness is $\sim 1 \mathrm{~nm}$ and the lateral dimensions of these layers may vary from $30 \mathrm{~nm}$ to several micrometres and even larger depending on the particular layered silicate. Stacking of the layers leads to a regular van der Waals gap between the layers called the interlayer or gallery. Isomorphic substitution within the layers (for example, $\mathrm{Al}^{+3}$ replaced by $\mathrm{Mg}^{+2}$ or by $\mathrm{Fe}^{+2}$, or $\mathrm{Mg}^{+2}$ replaced by $\mathrm{Li}^{+1}$ ) generates negative charges that are counterbalanced by alkali and alkaline earth cations situated inside the galleries, as shown in Fig. 2 and Table 2.

The most commonly used layered silicates are MMT hectorite and saponite with different chemical formula respectively, $\mathrm{M}_{\mathrm{x}}\left(\mathrm{Al}_{4-\mathrm{x}} \mathrm{Mg}_{\mathrm{x}}\right) \mathrm{Si}_{8} \mathrm{O}_{20}(\mathrm{OH})_{4}, \mathrm{M}_{\mathrm{x}}\left(\mathrm{Mg}_{6-\mathrm{x}} \mathrm{Li}_{\mathrm{x}}\right)-$ $\mathrm{Si}_{8} \mathrm{O}_{20}(\mathrm{OH})_{4}$ and $\mathrm{M}_{\mathrm{x}}\left(\mathrm{Si}_{8-\mathrm{x}} \mathrm{Al}_{\mathrm{x}}\right) \mathrm{Si}_{8} \mathrm{O}_{20}(\mathrm{OH})_{4}(x=0 \cdot 5-1 \cdot 2)$. The type of clay is characterised by a moderate surface charge - cation exchange capacity (CEC of 80120 mequiv/100 g) and layer morphology. These clays are only compatible with hydrophilic polymers, such as poly(ethyleneoxide) (PEO) and poly(vinylalcohol) (PVA). To improve compatibility with other polymer matrixes, one must convert the normally hydrophilic silicate surface to organophilic, which makes possible intercalation of many engineering polymers. Generally, this can be carried out by ion exchange reactions with cationic surfactants including primary, secondary, tertiary and quaternary alkyl ammonium or alkylphosphonium cations. The role of alkylammonium or

Table 1 Thermoplastic olefin (TPO) nanocmposites: application for automotive parts*

HUMMER H2 SUT: most recent nanocomposite application

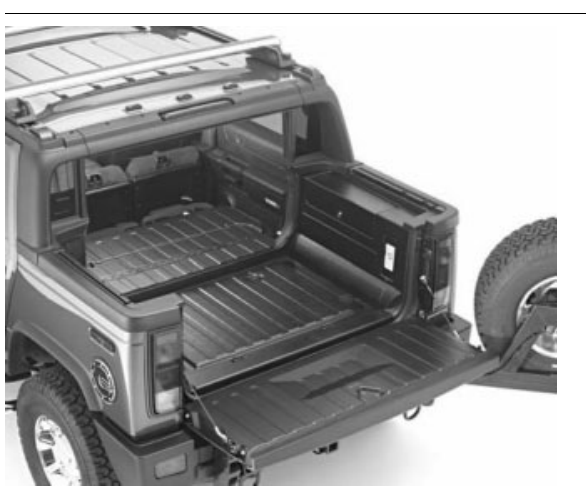

Nanocomposite TPOs summary of tangible benefits

Mass savings of $3-21 \%$

- Specific gravity of 0.92 versus $0.96-1.13 \mathrm{~g} \mathrm{~cm}^{-3}$

- Lighter weight reduces cost and requires less adhesive for attachment

Improved appearance

- Improved knit line appearance

- Improved colourability and paintability

- Sharper feature lines and grain patterns

- Improved scratch/mar performance

Large processing window

- Consistent physical and mechanical properties

- Elimination/reduction of tiger striping

Reduced paint delamination

Retains low temperature ductility

Improved recyclability

Lower flammability
M-van step assist: the first commercial launch
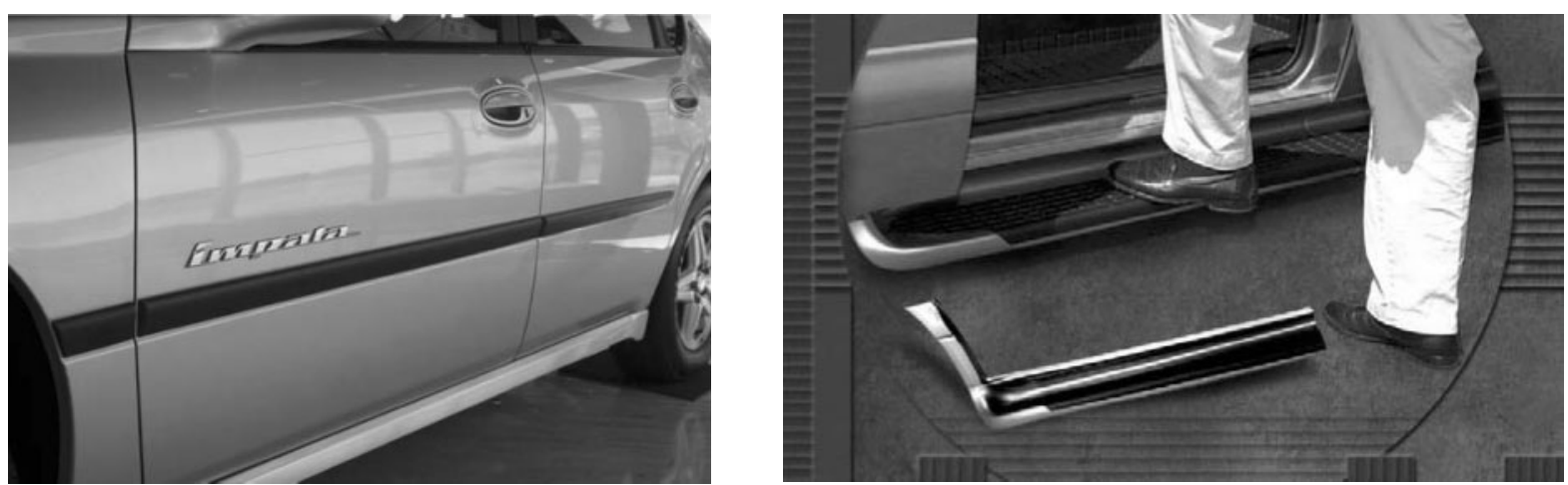

*Through the courtesy of M. Verbrugge, General Motors. 


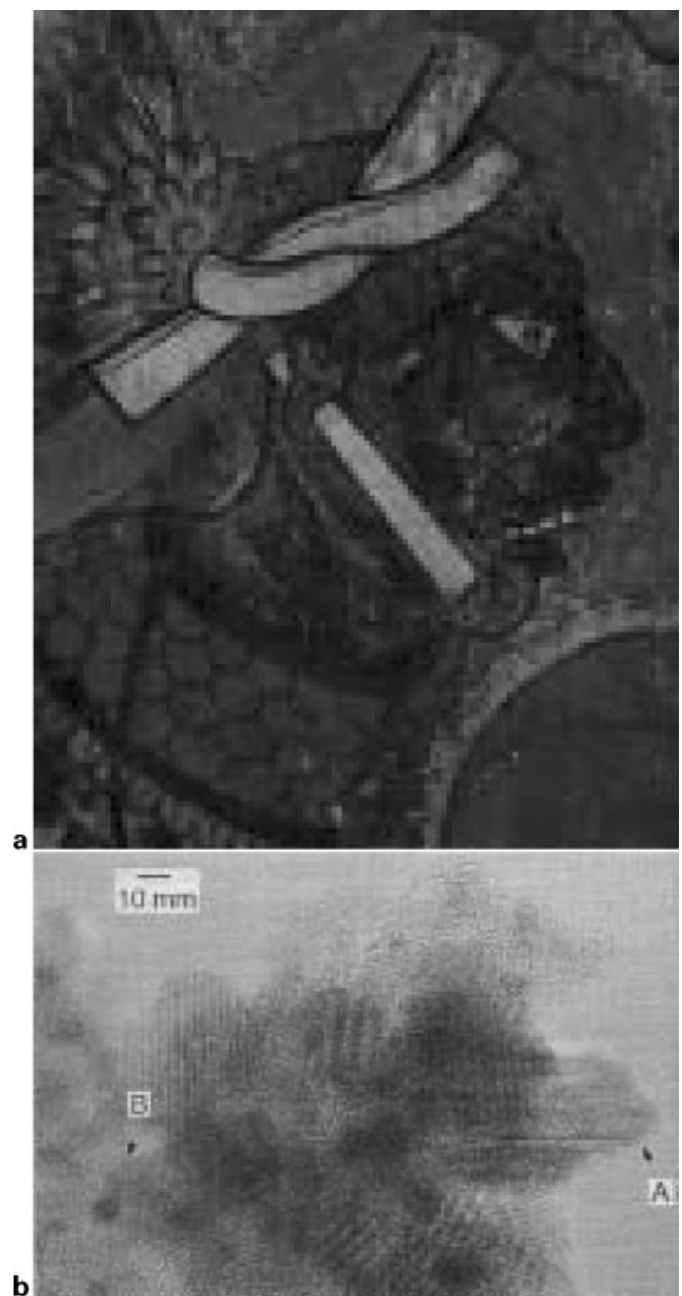

1 a Maya blue was used in this mural representing solider from Msoamerica and $b$ needle shape of palygorskite crystals. Reprinted with permission from Ref. 9, ( ) 1996, American Association for the Advancement of Science

Table 2 Clay mineral (phyllosilicates) classification

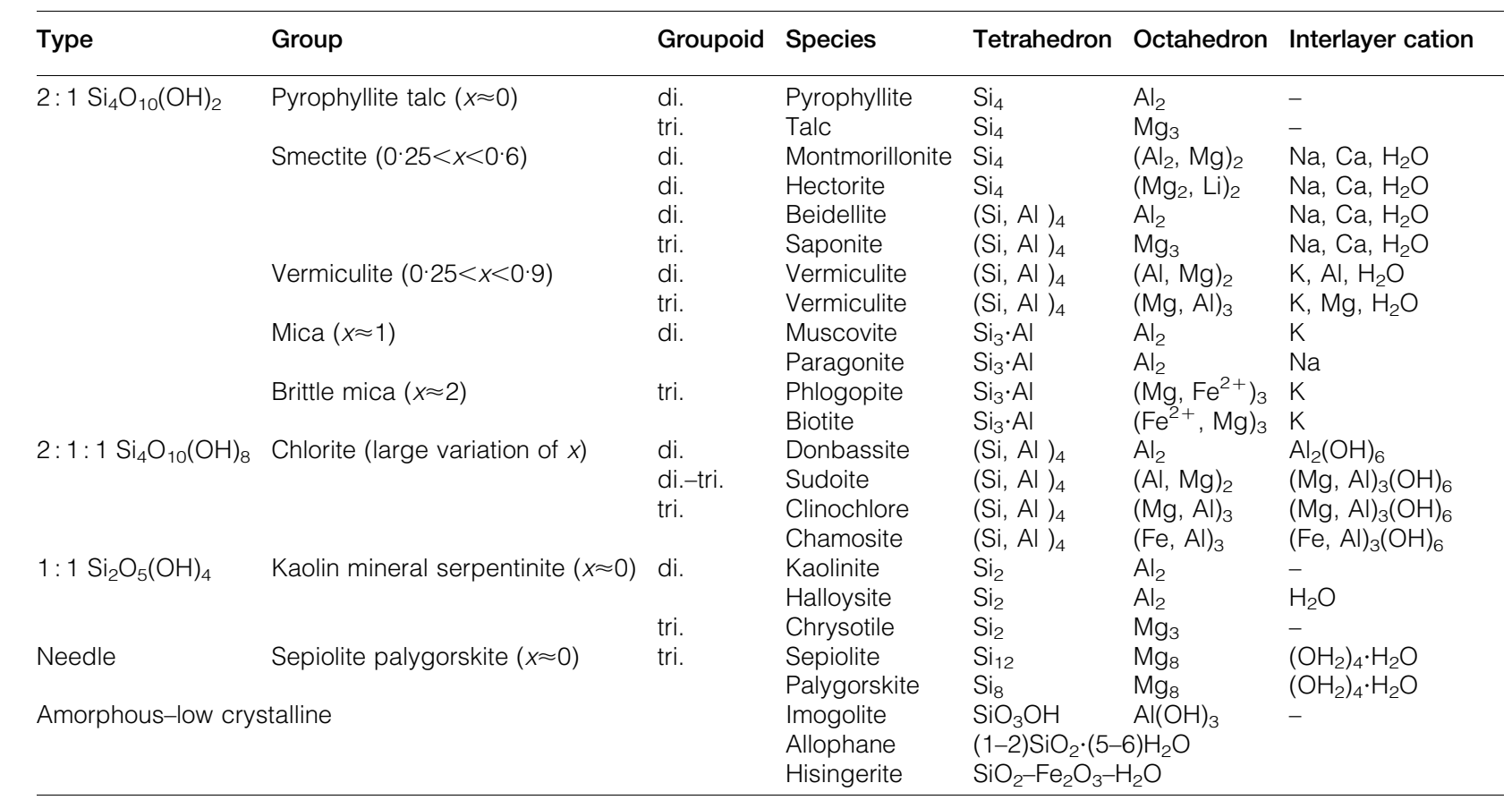

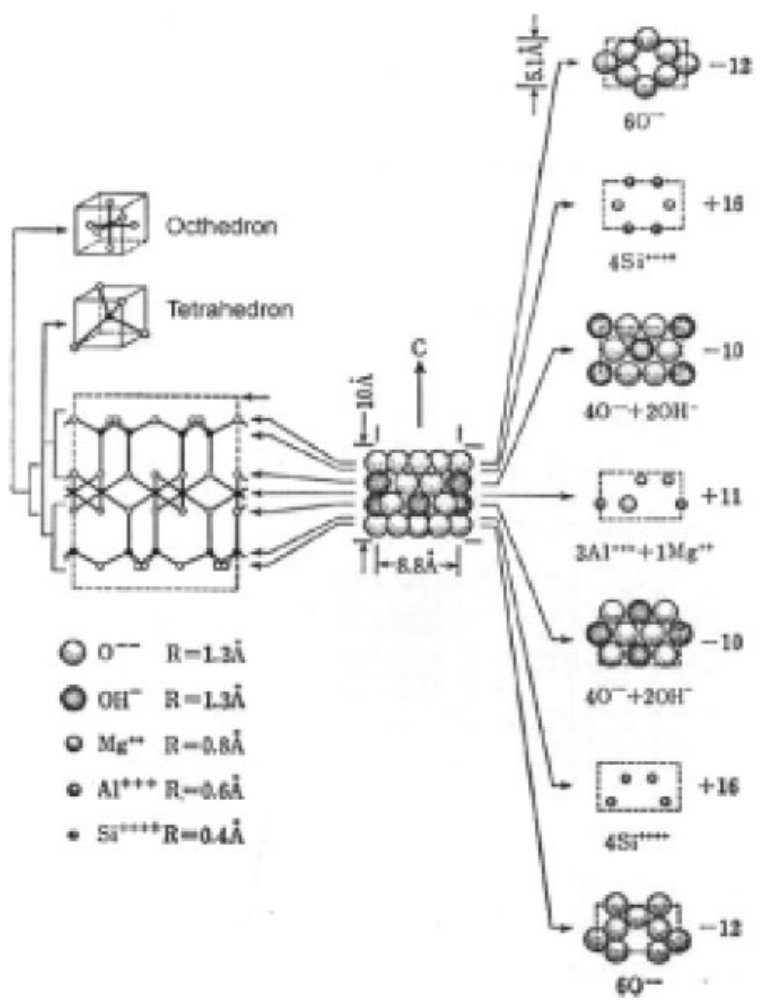

2 Structure of 2:1 phyllosilicates (montmorillonite)

alkylphosphonium cations in the organosilicates is to lower the surface energy of the inorganic host and improve the wetting characteristics with the polymer matrix, and results in a larger interlayer spacing. One can evaluate a $\mathrm{Na}^{+}$density of $0.7 \mathrm{Na}^{+} / \mathrm{nm}^{2}$, i.e. 7000 alkylammonium salt molecules are localised near the individual silicate layers (about $100 \times 100 \mathrm{~nm}^{2}$ ) and active surface area (about $700-900 \mathrm{~m}^{2} \mathrm{~g}^{-1}$ as determined by Braunauer-Emmett-Teller (BET)). This result indicates the organoclay platelets are hairy plates. Furthermore, the surface hydroxyl concentration of

\footnotetext{
$x$ : degree of isomorphous substitution; di.: dioctahedral; tri.: trioctahedral.
} 


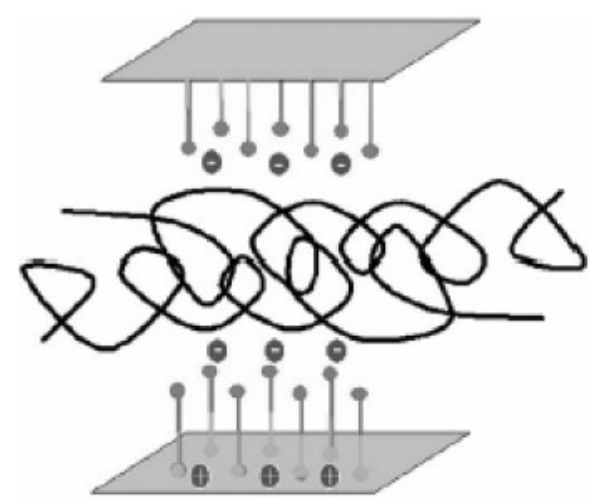

3 Principle of repulsion of sheet like nanoparticles via surface modification with bifunctional molecules. Reprinted with permission from Ref. 17, ๑ 2003, Elsevier Science

clays was determined by titration with triethyl aluminium. Assuming that the hydroxyl groups are randomly distributed on the edge surface, a Si-OH density of $5 \mathrm{Si}-$ $\mathrm{OH} / \mathrm{nm}^{2}$ can be calculated, ${ }^{10}$ i.e. $500-\mathrm{OH}$ groups are localised near the edge surface of the individual silicate layers (about $1 \times 100 \mathrm{~nm}^{2}$ ). This lipophilic-hydrophobic balance is the key issue of the fine dispersion of the organoclay platelets into the polymeric matrixes. Additionally, the alkylammonium or alkylphosphonium cations could provide functional groups that can react with the polymer matrix or in some cases initiate the polymerisation of monomers to improve the strength of the interface between the inorganic and the polymer matrix. $^{11,12}$

Because the thermal degradation of many organophilic clays occurs at temperature $>200^{\circ} \mathrm{C}$, clays with enhanced thermal stability are desired. Recent approach is polymerically modified clays. ${ }^{13-16}$ Poly(diallylammonium) salt and oligomeric styrene based ammonium salt have been prepared and used to produce PLSNCs. More interesting idea of the introduction of a repulsion of the single clay layers against each other is reported by Fischer (see Fig. 3). ${ }^{17}$ The cations located in between the clay platelets are ion exchanged by one of the functional groups on these organic molecules, e.g. an ammonium group, leaving another functional group, which can be positively or negatively charged, present on the clay layers. 4-amino-1-naphthalenesulphonic acid is one of the candidates.

\section{Nobel compounding process}

Hasegawa and Usuki ${ }^{18}$ reported a novel compounding process using the $\mathrm{Na}^{+}$-MMT slurry and demonstrated preparation of a nylon 6 nanocomposite, where the silicate layers exfoliated and homogeneously dispersed at nanometre level. The most merit of this compounding process is that the PLSNC consisted of nylon 6 and $\mathrm{Na}^{+}$-MMT is prepared without any surfactants of the clay minerals and additives. However, it is difficult to prepare a completely exfoliated nanocomposite by this method (see Fig. 4). Originally the perfect exfoliation of the silicate platelets may not be impossible owing to the strong interaction between hydroxylated edge-edge groups, and the clay platelets are sometimes flocculated in any polymer matrixes as reported by van Olphen ${ }^{19}$

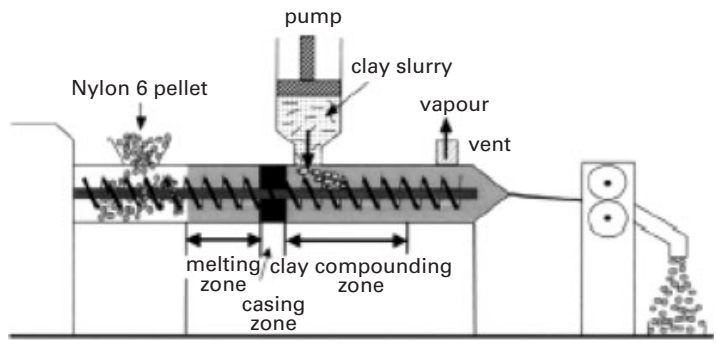

4 Schematic representation depicting compounding process for preparing the nylon 6 nanocomposites using clay slurry: nylon 6 was put into the extruder at $2 \mathrm{~kg} \mathrm{~h}^{-1}$ and melted in melting zone; clay slurry was pumped into cylinder of the extruder at $2 \mathrm{~kg} \mathrm{~h}^{-1}$ and compounded with melting nylon 6 in compounding zone at $240-250^{\circ} \mathrm{C}$; screw rotation speed was

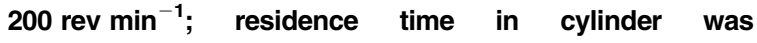
$\sim 10 \mathrm{~min}$; sealing zone was set by sealing ring to prevent water back flow for hopper; water of slurry was removed from vent by vacuum to obtain nanocomposites. Reprinted with permission from Ref. $18 \odot 2003$, Elsevier Science

(see section on 'Flocculation control and modulus enhancement').

Recently, an in situ polymerisation method used supercritical $\mathrm{CO}_{2}\left(\mathrm{sc}-\mathrm{CO}_{2}\right)$ as a processing aid to achieve a uniform distribution in a PLSNC at high clay loading $(\sim 40 \mathrm{wt}-\%))^{20}$ Zhao et al. ${ }^{21}$ presented unambiguous evidence for sc- $\mathrm{CO}_{2}$ mediated intercalation of PEO into $\mathrm{Na}^{+}-$MMT compared with polymer intercalation in solution, in which an entropy driven process is dominant. This mechanism is probably similar to that in polymer melts. Therefore, the sc- $\mathrm{CO}_{2}$ mediated intercalation is an enthalpically driven process, deriving from a favourable intercalation between PEO and MMT.

\section{Nanostructure properties control Intercalation during crystallisation and confinement}

Recently, Maiti et al. ${ }^{22}$ reported that in the polypropylene/LS nanocomposites (PPCNs) at high crystallisation temperature $T_{\mathrm{c}} \geqslant 110^{\circ} \mathrm{C}$, where the crystallisation rate is low enough to solidify the system, the intercalation should be anticipated in the melt state during crystallisation. The driving force of the intercalation originates from strong hydrophilic interaction between the maleic anhydride (MA) group and the polar clay surfaces. ${ }^{23}$ With increasing $T_{\mathrm{c}}$, the small peak and shoulder shift toward the smaller angle region in the PPCNs, suggesting that the extent of intercalation takes place with crystallisation. $^{22}$

Figure 5 shows the diffraction peak from the (001) planes $d_{(001)}$ of the clay gallery quantitatively, as a function of $T_{\mathrm{c}}$, obtained from their respective Bragg reflections. Here, in the case of PPCN2 (including $2 \mathrm{wt}-\%$ inorganic clay), the peak is not prominent. The dotted line shows the effect of annealing on the $d_{(001)}$ value of organoclay. The $d_{(001)}$ increases with $T_{\mathrm{c}}$ for both PPCN4 and PPCN7.5 systems, and PPCN4 always exhibits significantly higher value than PPCN7.5. This implies that intercalation proceeds at $T_{\mathrm{c}}$ and increases with decreasing clay content. Further decrease in clay 


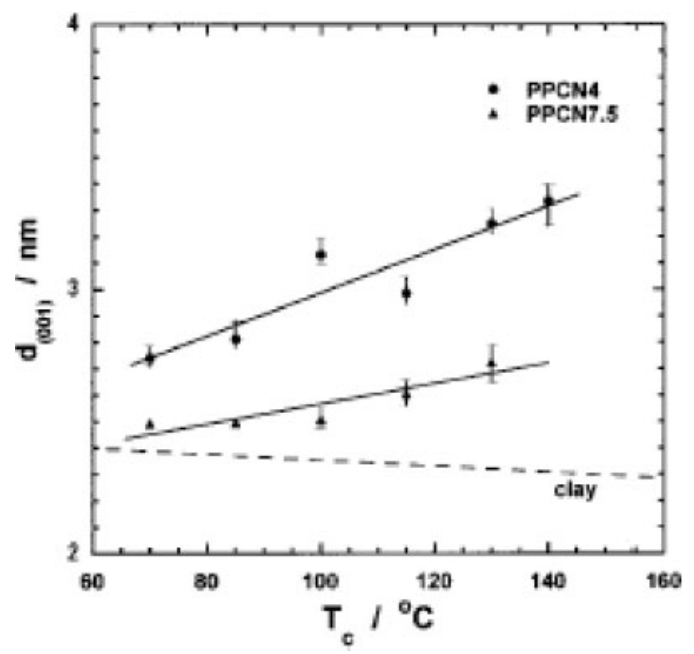

$5 \quad T_{c}$ dependence of interlayer spacing of PPCN4 and PPCN7.5: broken line shows annealing effect on organoclay. Reprinted with permission from Ref. 22, ( ) 2002, American Chemical Society

content from 4 to $2 \mathrm{wt}-\%$ in PPCN2 leads to a partially exfoliated system as discussed in the literature. ${ }^{23}$ That is, the PPCN with low clay content crystallised at high $T_{\mathrm{c}}$ $\left(\geqslant 110 \cdot 0^{\circ} \mathrm{C}\right)$ exhibits higher amount of intercalation than that with high clay content crystallised at any $T_{\mathrm{c}}$.

At high $T_{\mathrm{c}}\left(\geqslant 110^{\circ} \mathrm{C}\right)$ (low crystallisation rate), the melt state exists for quite a long time and PP-MA chains have enough time to intercalate before crystallisation can occur in the bulk. Then, the enhanced intercalation is produced. The extent of intercalation is strongly dependent on the time of the molten state. In other words, the intercalated PPCNs are not equilibrated. By decreasing the clay content in the nanocomposites, the virtual gallery space in the silicate layers decreases and consequently, the PP-MA molecules would try to accommodate, through interaction, in the minimum space causing higher intercalated species. For sufficiently low clay content, a system, like PPCN2, with less gallery space, is partially exfoliated owing to high number density of tethering junction.

There are two possible ways of ordering of polymer chains inside the silicate gallery by either polymer molecules escape from gallery and crystallise outside (diffuse out) or molecules may penetrate into the silicate gallery when they are in the molten state (diffuse in).

When PPCN4 is directly crystallised from the melt at $70.0^{\circ} \mathrm{C}$ for two different times of $30 \mathrm{~min}$ and $17 \mathrm{~h}$, the interlayer spacing is the same $(2 \cdot 75 \mathrm{~nm})$. If PPCN4 melt is annealed at $150 \cdot 0^{\circ} \mathrm{C}$, just above melting temperature $T_{\mathrm{m}}$ $\left(145 \cdot 0^{\circ} \mathrm{C}\right)$ for sufficiently long time and then subsequently crystallised at $70 \cdot 0^{\circ} \mathrm{C}$ for $30 \mathrm{~min}$, the interlayer spacing increases to $2.96 \mathrm{~nm}$. Furthermore, when PPCN4 is crystallised from the melt at $30^{\circ} \mathrm{C}$, where crystallisation rate is slow enough, the interlayer spacing becomes $3.08 \mathrm{~nm}$. All these experiments indicate that the extent of intercalation is strongly dependent on the time of the molten state and ordering of polymer chains occurs through a diffuse in mechanism. In other words, a slower crystallisation rate makes a more intercalated species as molten polymer molecules have sufficient time to diffuse into the silicate gallery. Based on the wide angle X-ray diffraction (WAXD) and TEM micrographs, the nature of intercalation has been represented by Maiti and Okamoto $^{22,24}$ in Fig. 6. Therefore, by suitably crystallising the PPCNs, the fine structure (confined orientation) of the PLSNCs can be controlled.

According to Khare's prediction, ${ }^{25}$ the confinement of polymer chains increases the viscosity and mechanical properties of the system significantly. Some difference in mechanical properties with the change of the degree of intercalation in the PPCNs vis-à-vis the clay content and $T_{\mathrm{c}}$ can be expected (see Table 3 ). It is clear from Table 3 that for a particular $T_{\mathrm{c}}$, the dynamic storage modulus $G$, increases with increasing clay content. The PP-MA crystallised at $130^{\circ} \mathrm{C}$ exhibits a $9.9 \%$ increase in $G$, compared with the sample crystallised at $70 \cdot 0^{\circ} \mathrm{C}$. The PPCN7.5 and PPCN 4 show $13 \cdot 3$ and $30 \cdot 6 \%$ increases
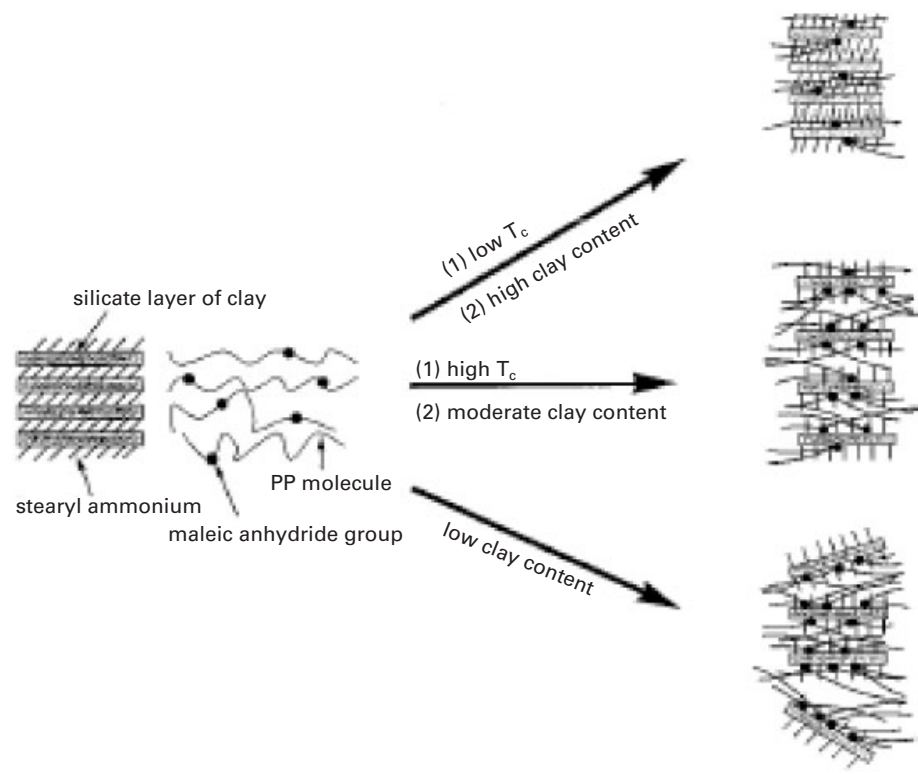

6 Illustration of diffusion mechanism by suitable crystallisation. Reprinted with permission from Ref. 22, () 2002, American Chemical Society 

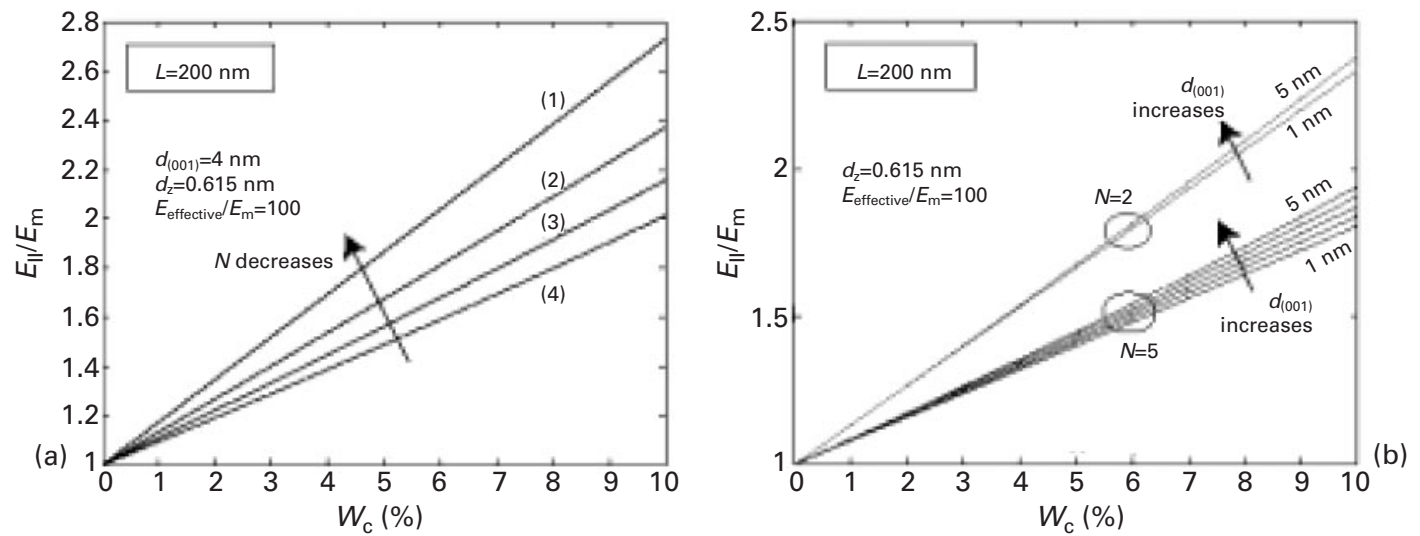

a effect of $N$ at fixed $d_{(001)}=4.0 \mathrm{~nm} ; b$ effect of $d_{(001)}$ at two fixed values $N=2$ and $N=5$

7 Effect of clay structural parameters $\left(N, d_{(001)}\right)$ on macroscopic modulus predicted by Mori-Tanaka model. Reprinted with permission from Ref. 26, ๑ 2004, Elsevier Science

respectively in the same condition. The effect of $T_{\mathrm{c}}$ on the $G^{\prime}$ is in the order of PP-MA $<$ PPCN7.5 $<$ PPCN4. It may be recalled that the $T_{\mathrm{c}}$ dependence of $d_{(001)}$ showed the order of intercalation PPCN7.5 $<$ PPCN4 in Fig. 5. This implies that much higher efficiency of the intercalation for the reinforcement is attained in the PPCN4. For PPCN2, owing to the partial exfoliation, the degree of intercalation decreases, and hence the modulus decreases compared with the low $T_{\mathrm{c}}$ condition $\left(=70^{\circ} \mathrm{C}\right)$. Here, it should be mentioned that the crystallinity increases little bit with increasing $T_{\mathrm{c}}$ for both PPMA and PPCNs and the extent is almost the same for all the systems. Therefore, it is believed that not the crystallinity, but the degree of intercalation does affect on the storage modulus.

\section{Multiscale micromechanical modelling}

Very recently, Sheng and Boyce ${ }^{26}$ reported a multiscale modelling strategy to account for the hierarchical morphology of the nanocomposite: at a lengthscale of thousands of micrometres, the structure is one of high aspect ratio particles within a matrix; at the lengthscale of micrometres, the clay particle structure is either exfoliated clay sheets of nanometre level thickness or stacks of parallel clay sheets separated from each other by interlayer galleries of nanometre level height, and the matrix, if semicrystalline, consists of fine lamella, oriented with respect to the polymer/nanoclay interfaces. Models of various representative volume elements of the underlying structure of the clay filled polymer are constructed. Figure 7 shows the influence of internal clay structural parameters (the average number of silicate layers per clay stack: $\left.N, d_{(001)}\right)$ on the macroscopic

Table 3 Dynamic storage modulus of PP-MA and PPCNs at $T=50^{\circ} \mathrm{C}$ crystallised at different temperatures $^{22}$

\begin{tabular}{lrll}
\hline System & $\boldsymbol{T}_{\mathbf{c}},{ }^{\circ} \mathbf{C}$ & $\mathbf{G}^{\prime}, \times \mathbf{1 0}^{-\mathbf{8}} \mathbf{P a}$ & Increase, \% \\
\hline PP-MA & 70 & 2.92 & 9.9 \\
& 130 & 3.21 & \\
PPCN2 & 70 & 4.79 & \\
& 130 & 4.50 & 30.6 \\
PPCN4 & 70 & $5 \cdot 16$ & \\
& 130 & $6 \cdot 74$ & 13.3 \\
PPCN7.5 & 70 & $7 \cdot 49$ & \\
& 130 & 8.49 & \\
\hline
\end{tabular}

modulus of the PLSNC. The enhancement of modulus $E_{11} / E_{\mathrm{m}}$ is plotted as a fuction of clay content $W_{\mathrm{c}}$ and $N$ at fixed $d_{(001)}$. The strong dependence of modulus on $N$ is cleary demonstrared; at a fixed $W_{\mathrm{c}}$, modulus increases with decreasing $N$; the amount of increase gradually expands as $N \rightarrow 1$. On the other hand, the effect $d_{(001)}$ on the modulus for two different values of $N(N=2$ and 5). Compared with $N$, the influence of $d_{(001)}$ on modulus is rather small and depends on the specific value of $N$. This increment is rather negligible when $N$ is small, however, when the nanocomposite is highly intercalated (e.g. $N=5$ ), the increase in a few nanometres in $d_{(001)}$ can cause a considerable increase in modulus.

In the case of nylon 6, the transcrystallisation behaviour induced by the nanoclay is taken into account by modelling a layer of matrix surrounding the particle to be highly textured and therefore mechanically anisotropic. Micromechanical models (numerical and analytical) based on the 'effective clay particle' were employed to calculate the overall elastic modulus of the amorphous and semicrystalline PLSNCs and to compute their dependence on the matrix and clay properties as well as internal clay structural parameters. The proposed modelling technique captures the strong modulus enhancements observed in elastomer/clay nanocomposites as compared with the moderate enhancements observed in glassy and semicrystalline PLSNCs. For the case where the matrix is semicrystalline (like nylon 6), the proposed approach captures the effect of transcrystallised matrix layers in terms of composite modulus enhancement, however, this effect is found to be surprisingly minor in comparison with the composite level effects of stiff particles in a matrix. This reason is discussed in Section 'Higher-order structure development and crystallisation controlled by silicate surfaces'.

Note that in order to determine the nanocomposite modulus, the modulus of nanoclay of $400 \mathrm{GPa}$ is employed. Most of the nanocomposite researchers believe that the nanoclay has a high modulus of $170 \mathrm{GPa}^{2}$ However, this value is absolutely acceptable or not even though in the case of monolayered clay sheet.

\section{Flexibility of single clay layer}

A large degree of flexibility of the monolayered clay sheet is reported. ${ }^{27}$ Two transmission electron microscope (TEM) images are evident (see Fig. 8). One arises 

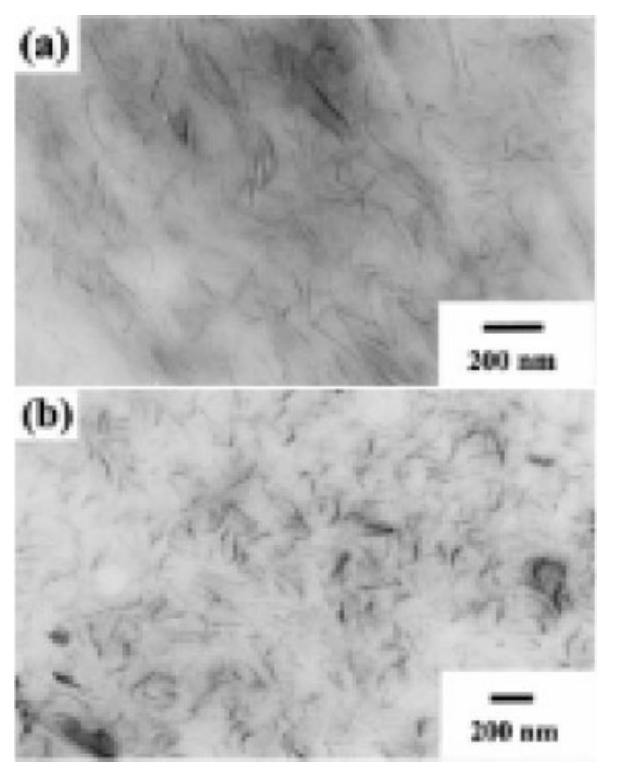

a 2 wt-\%MMT; b 4 wt-\%MMT

8 Bright field TEM images of PPCNs: dark lines are cross-sections of silicate layers and bright areas are PP-MA matrix. Reprinted with permission from Ref. 23, ๑) 2001, Elsevier Science

from the clay layers that appear as about 150-200 nm curved sheets. When viewed edge on as shown in Fig. $8 b$, several 5-8 $\mathrm{nm}$ stacked sheets are apparent. The curved nature of the sheet is observed, for it is well known that smectite clay sheet have a large degree of flexibility. ${ }^{27}$ Sato and Kawamura ${ }^{28}$ reported the study of the flexibility of smectite clay minerals by molecular dynamics (MD) simulations. They took into account the quantitative understanding of the mechanical behaviour of a single clay layer in a completely exfoliated state. The repeating unit of a layer is taken to be $a_{0}=0.52 \mathrm{~nm}$ and $b_{0}=0.902 \mathrm{~nm}$ with formula of $2 \mathrm{Na}_{1 / 3} \mathrm{Al}_{2}\left[\mathrm{Si}_{11 / 3} \mathrm{Al}_{1 / 3}\right]-$ $\mathrm{O}_{10}(\mathrm{OH})_{2}$, which corresponds to that of beidellite (see Table 2). When the size of the basic cell $(A=9.3 \mathrm{~nm}$, $\mathrm{B}=2 \cdot 6 \mathrm{~nm}$, and $\mathrm{C}=5 \mathrm{~nm}$ ) (A type cell) is reduced by 3 $40 \%$ in the A direction, the stationary structure of a clay layer is obtained as a curved sheet with a $2: 1$ smectite type layer. In such curved state, the layer experiences an external stress of $0.5-0.7 \mathrm{GPa}$. The layer structure of a clay fractures when the size of the same basic cell is reduced by $>40 \%$. This value is much lower than that of muscovite $(\sim 2 \mathrm{GPa})$ which is also reported by the same authors. ${ }^{29}$ The simulation has also been performed by reducing the size of the basic cell $(A=3 \cdot 1 \mathrm{~nm}, \mathrm{~B}=$ $10 \cdot 7 \mathrm{~nm}$, and $\mathrm{C}=5 \mathrm{~nm}$ ) (B type) in the $\mathrm{B}$ direction. The clay layer is found to be more flexible along the A direction than along the $\mathrm{B}$ direction. When the microscopic structure of a curved clay layer is examined, it is concluded that the main origin of the flexibility lies in the change of $\mathrm{Si}-\mathrm{O}-\mathrm{Si}$ angle in the silicate tetrahedral sheets rather than in the change of bond lengths. These simulation results agree with the atomic force microscopy (AFM) observations. ${ }^{30}$

\section{Higher order structure development and crystallisation controlled by silicate surfaces}

The formation of $\gamma$ form in presence of clay in nylon 6/LS nanocomposite is well known. ${ }^{31}$ The essential difference between $\gamma$ form and $\alpha$ form is the molecular packing; in the $\alpha$ form, hydrogen bondings are formed between antiparallel chains, while the molecular chains have to twist away from the zigzag planes to form the hydrogen bonds among the parallel chains in $\gamma$ form giving rise to lesser interchain interaction as compared with $\alpha$ form.

The lamellar morphology and distribution of clay particles in the nylon 6 nanocomposite (N6CN3.7) $(\mathrm{MMT}=3.7 \mathrm{wt}-\%)$, crystallised at 170 and $210 \cdot 0^{\circ} \mathrm{C}$, have been reported by Okamoto and Maiti, ${ }^{32}$ as shown in Fig. 9. The white strips (Fig. 9a) represent the discrete lamellar pattern, and after a close look, a black clay particle inside the lamella is clearly observed. In other words, lamellar growth occurs on both sides of the clay particles, i.e. the clay particles are sandwiched by the formed lamellae. This is a unique observation of lamellar orientation on the clay layers. In the semicrystalline polymer generally the stacked lamellar orientation takes place. Figure $9 b$ shows the typical shish kebab type of structure. The lamellar pattern at high $T_{\mathrm{c}}$ (Fig. $9 b$ ) is somehow similar but along with the sandwiched structure, branched lamellae are formed, which are originated from the parent sandwiched lamella. There are no clay particles found inside the branch lamella, and the $\gamma$ phase having irregular chain packing with distortion ( $\gamma^{*}$ phase) is formed as revealed by wide angle X-ray diffraction (WAXD), by which one
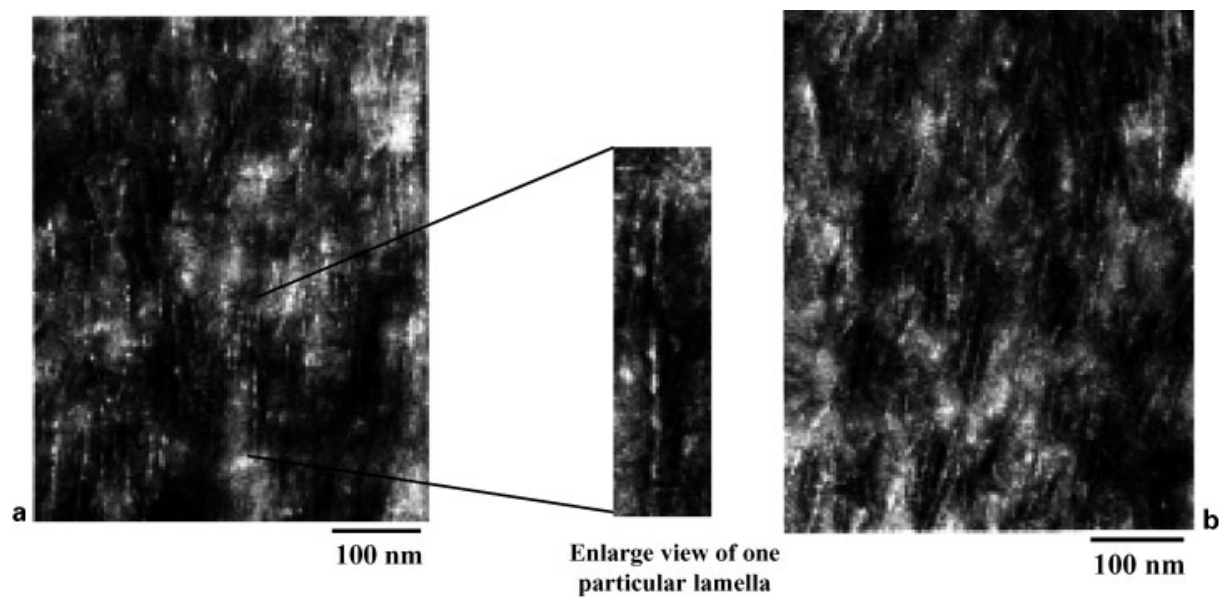

9 Images (TEM) of N6CN3.7 crystallised at $a 170$ and $b 210^{\circ} \mathrm{C}$ : black strip inside white part is clay. Reprinted with permission from Ref. 32, ๑ 2003, Wiley-VCH 


\section{$17.2 \AA$}

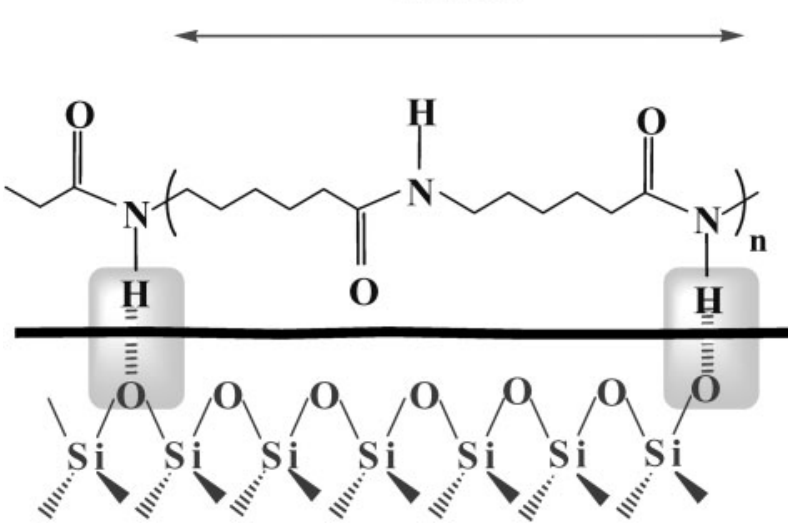

10 Schematic view of nucleation and growth mechanism in N6CN3.7. Reprinted with permission from Ref. 32, (๑) 2003, Wiley-VCH

can observe only in the case of high $T_{c}$ crystallised N6CN3.7. This epitaxial growth $\left(\gamma^{*}\right.$ phase) on the parent lamella forms the shish-kebab type of structure, which virtually enhance the mechanical properties of the nanocomposites like a bone material which consists of collagen fibrils reinforced with tiny mineral particles, a few nanometres in thickness. ${ }^{33}$

From this sandwiched structure, the accurate determination of long spacing and lamellar thickness of N6NC3.7 from small angle X-ray scattering (SAXS) is questionable. $^{34,35}$ It has to be remembered that nylon 6 has the highest capability of forming hydrogen bonding to form hydrogen bonded sheet. The pseudohexagonal packing is favoured with the hydrogen bonding between the silicate layers and nylon 6 , as a result the induction time of N6CN3.7 becomes very short, as compared with neat nylon 6. Once one molecular layer is nucleated on the clay surface, other molecules may form the hydrogen bonding on the already formed hydrogen bonded molecule to the silicate surface giving rise to the discrete lamellar structure on both sides of the clay. The nucleation and growth process have been demonstrated in Fig. 10, following direct observation by TEM. ${ }^{32}$ This unique mechanism can well explain the higher crystallisation rate of PLSNCs along with morphology and developed internal structure. This sandwiched structure (each silicate layer is strongly covered by polymer crystals) makes the system very rigid, as a result the heat distortion temperature (HDT) increases up to $80^{\circ} \mathrm{C}$, but the surrounding excess amorphous part (lower crystallinity of $\mathrm{N} 6 \mathrm{CN} 3.7$ as compared with neat nylon 6) can easily retain the polymeric properties like impact strength, ultimately makes a improved/perfect system in PLSNCs.

Kim and Kressler $^{36}$ also reported that the fine lamellae of nylon 12 crystals are oriented perpendicularly to the nylon 12/LS interface, i.e. on planes lying normal to the injection moulding direction. This interfacial ordering may be a result of the crystallisation process and similar to the well known transcrystallisation. ${ }^{37}$ The nanocomposites consist of a nanostructured network finely dispersed and uniformly oriented silicate layers are aligned perpendicular to lamellae, and the two materials are strongly bonded to each other (see Fig. 11). In these nylon nanocomposites, the nanoclay

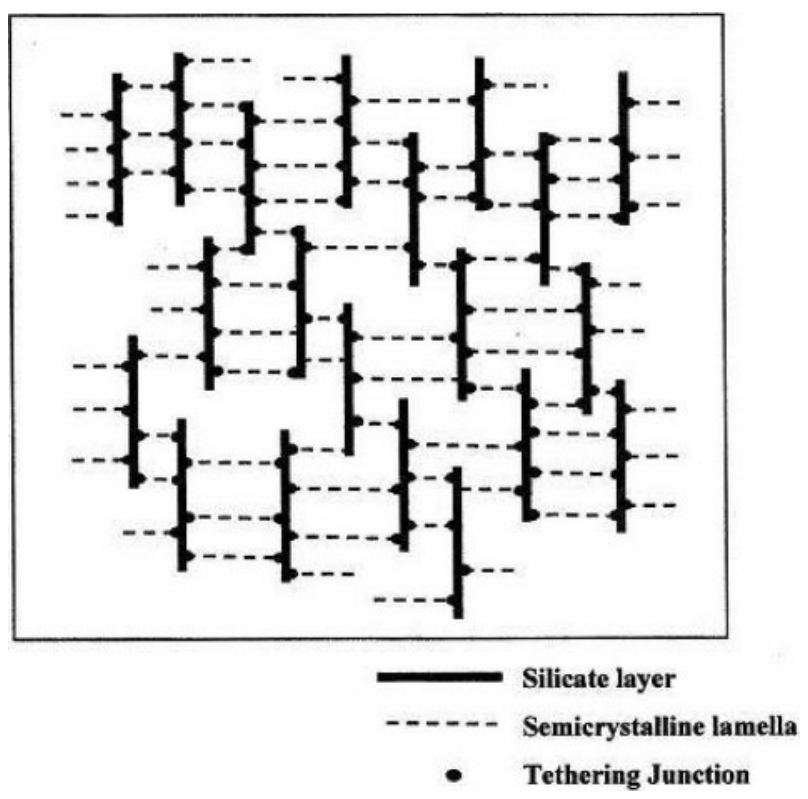

11 Nanostructured network in nylon 12/LS nanocomposite. Reprinted with permission from Ref. 36, (c) 2001, Elsevier Science

particles with the sandwiched and network (shish-kebab) structure have a high function as microvoid initiation sites, which are necessary for high toughness during deformation. Very recently, Fratzl et al. ${ }^{38}$ reported that the mechanical behaviour of the collagen mineral nanocomposite in bone depends crucially both on components, mineral and wet collagen, and on their interaction (see Fig. 12).
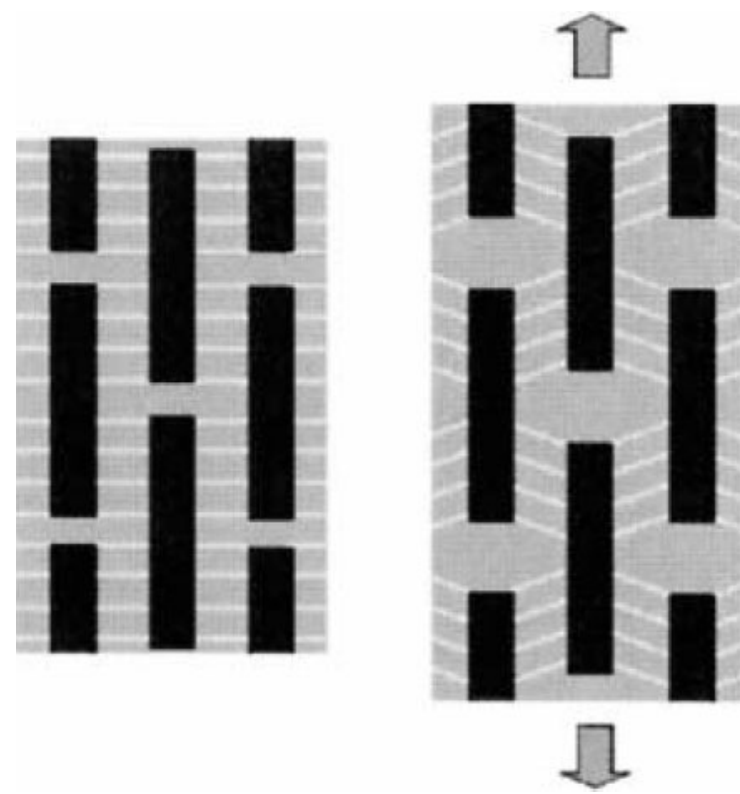

12

Schematic arrangement of mineral and organic phase in mineralised collagen fibril subjected to tensile load: mineral particles are shown in dark gray and should be imagined as platelets viewed edge on; horizontal white lines in light gray matrix (left part in figure) are not indicating any physical reality; they are just drawn to visualise shear deformation in matrix between particles as consequence of tensile deformation of tissue (right part of figure). Reprinted with permission from Ref. 38, (c) 2004, The Royal Society of Chemistry 


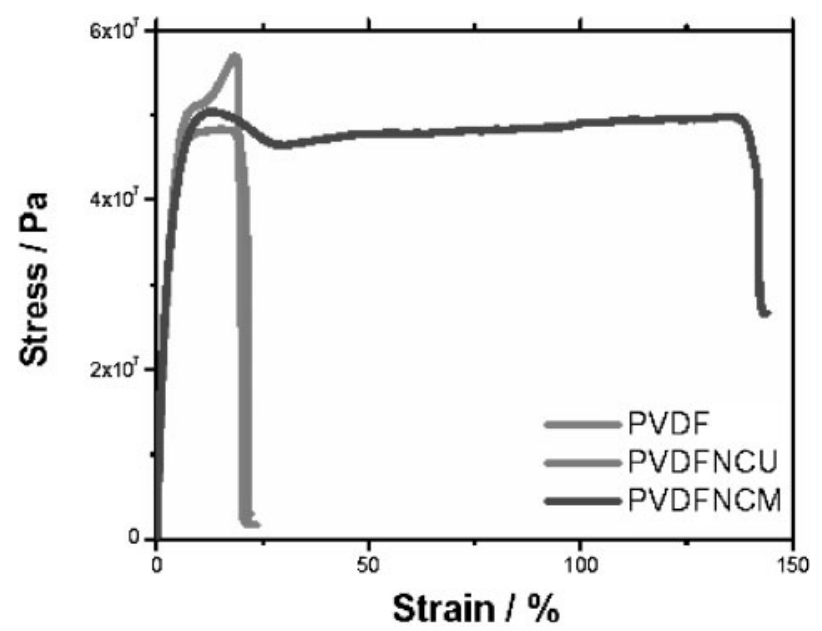

13 Stress-strain curves for neat PVDF ( $\alpha$ phase crystallite), PVDFNCU (microcomposite by MMT) and PVDFNCM (nanocomposite by organoclay) showing dramatic increase in elongation at break for nanocomposite. Reprinted with permission from Ref. 40, ๑ 2004, Wiley-VCH

In the case of polyvinylidene (PVDF)/LS nanocomposites, the formation of $\beta$ form has been observed. ${ }^{39,40}$ Shah et $a l^{40}$ reported a remarkable order of magnitude enhancement in toughness of the nanocomposites (see Fig. 13). They postulated that nucleation of the fiber like $\beta$ phase (more ductile than the $\alpha$ phase) on the surface of individual silicate layers leads to a structure conductive to plastic flow under applied stress. Energy dissipation could be further enhanced owing to the presence of more mobile $\beta$ crystallites which have a potential of acting like rigid fillers surrounded by the crystalline phase of PVDF. Therefore, the crystallisation controlled by silicate surfaces may provide not only a new approach for toughening of polymers but also the way towards a novel approach for the design of new materials.

In the case of polyester systems, Yamada et al. ${ }^{41}$ examined the HDT of various polylactide (PLA)/LS nanocomposites (PLACNs) with different load conditions. In the case of PLACN (MMT $=5 \mathrm{wt}-\%$ ), there is marked increase in HDT with intermediate load of $0.98 \mathrm{MPa}$, from $76^{\circ} \mathrm{C}$ for the neat PLA up to $111^{\circ} \mathrm{C}$ for PLACN (see Fig. 14). In the case of high load

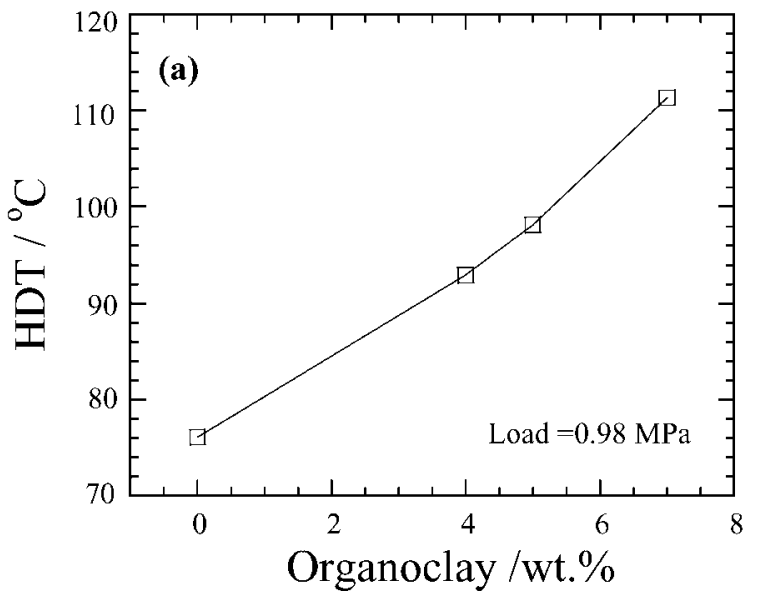

(1.81 MPa), however, it is very difficult to achieve high HDT enhancement without strong interaction between polymer matrix and organoclay like nylon systems. ${ }^{32}$ Therefore, the improvement of HDT with intermediate load $(0.98 \mathrm{MPa})$ originates from the better mechanical stability of the PLACNs owing to mechanical reinforcement by the dispersed clay particles and higher value of the degree of crystallinity $\chi_{c}$ and intercalation. This is qualitatively different from the behaviour of nylon systems, where the MMT layers stabilise in a different crystalline phase $(\gamma \text { phase })^{32}$ with the strong hydrogen bondings between the silicate layers and nylon 6 , as a result the discrete lamellar structure on both sides of the clay (see Figs. 9 and 10). Nylon/LS nanocomposites are successfully prepared without strategy for designing of materials with desired properties of the PLSNCs.

\section{Flocculation control and modulus enhancement}

Most of the nanocomposite researchers obdurately believe that the preparation of completely exfoliated structure is the ultimate target for better overall properties. However, these significant improvements are not observed in every nanocomposite systems, including systems where the silicate layers are near to exfoliated. ${ }^{42}$ While from the barrier property standpoint, the development of exfoliated nanocomposites is always preferred. On the other hand, Nylon/LS nanocomposite systems are completely different from other nanocomposite systems as discussed before.

In Fig. 15, Okamoto summarised the clay content dependence of dynamic storage modulus $G$ ' of various types of nanocomposites obtained under well below $T_{\mathrm{g}}$ of the matrixes. Einstein coefficient $k_{\mathrm{E}}$ derived by Halpin and Tai's theoretical expression modified by Nielsen is shown in Fig. 15, and represents the aspect ratio $L_{\text {clay }} / d_{\text {clay }}$ of dispersed clay particles without intercalation. From Fig. 15, it is clearly observed that poly(butylene succinate)(PBS)/LS nanocomposites (PBSCNs) show very high increment in $G^{\prime}$ compared with other nanocomposites with the same content of clay in the matrix. PPCNs are well known for intercalated systems, N6CNs are well established exfoliated nanocomposites, PLACNs are going to establish intercalated and flocculated nanocomposites, while PBSCNs are intercalated and extended flocculated nanocomposites systems. $^{43,44}$ Owing to the strong

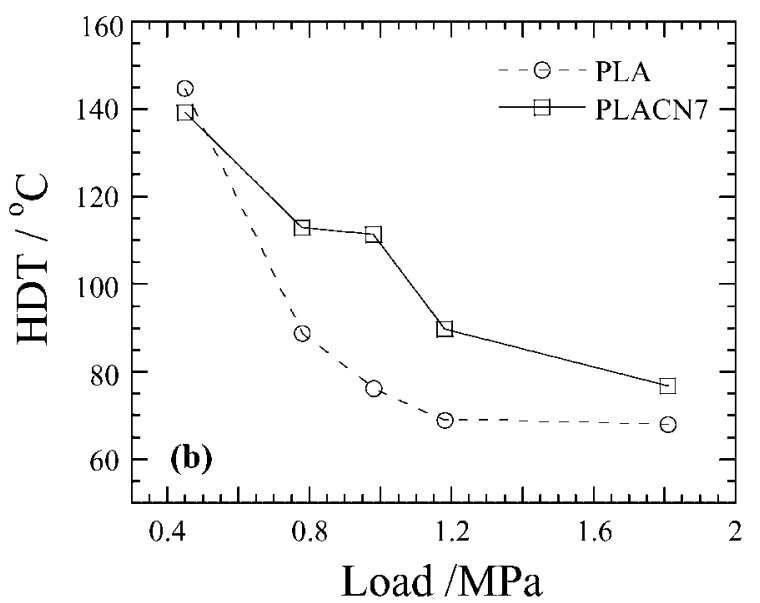

14 a Organoclay (wt-\%) dependence of HDT of neat PLA and various PLACNs and $b$ load dependence of HDT of neat PLA and PLACN7. Reprinted with permission from Ref. 41, ๑ 2003, Elsevier Science 


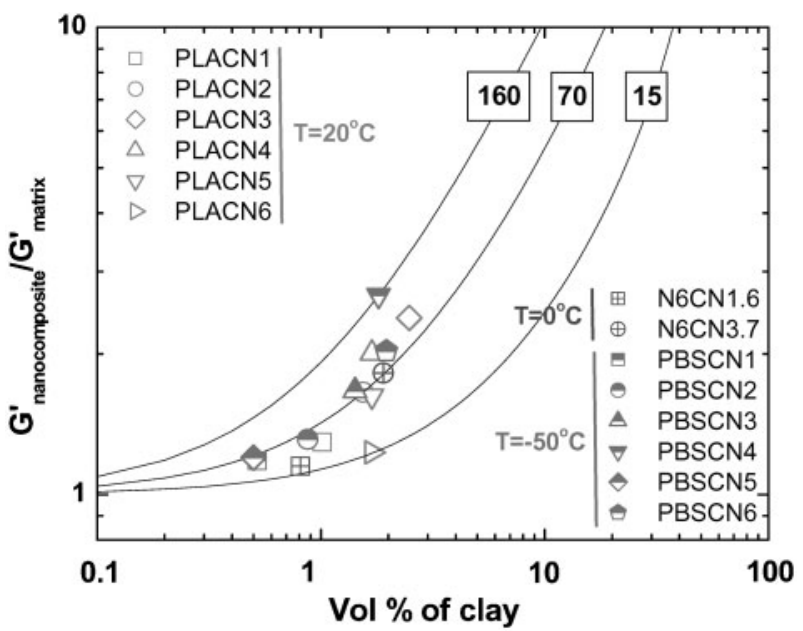

15 Plots of $G^{\prime}{ }_{\text {nanocomposite }} / G^{\prime}$ matrix versus vol.-\% of clay for various nanocomposites: Einstein coefficient $k_{\mathrm{E}}$ is shown with number in box; lines show calculated results from Halpin and Tai's theory with various $k_{E}$

interaction between hydroxylated edge-edge groups, as above mentioned, the clay particles are some time flocculated in the polymer matrix. As a result of this flocculation the length of the clay particles increases enormously and hence overall aspect ratio. For the preparation of high molecular weights PBS, diisocyanate $\left[\mathrm{OCN}-\left(\mathrm{C}_{6} \mathrm{H}_{12}\right)-\mathrm{NCO}\right]$ type end groups are generally used as a chain extender. These isocyanate end groups chain extender make urethane bonds with hrydroxy terminated low molecular weight PBS, and each high molecular weights PBS chain contain two such kind of bonds (see Fig. 16). These urethane type bonds lead to the strong interaction with silicate surface by forming hydrogen bonds and hence strong flocculation (see Fig. 17). For this reason, the aspect ratio of dispersed clay particles is much higher in the case of PBSCNs compared to all nanocomposites, and hence high enhancement of modulus.

This behaviour with the help of classical rheological theory of suspension of conventional filler reinforced systems can be explained. According to this theory, ${ }^{45}$ the rotation of filler is possible when volume fraction of clay $\phi_{\text {filler }}<\phi_{\text {critical }} \cong(\text { aspect ratio })^{-1}$. All PBSCNs studied here follow this relation except PBSCN4 (MMT= $3.6 \mathrm{wt}-\%)$, in which $\phi_{\text {filler }} \gg(\text { aspect ratio })^{-1}$. For this reason in PBSCN4 rotation of dispersed intercalated with flocculated stacked silicate layers is completely

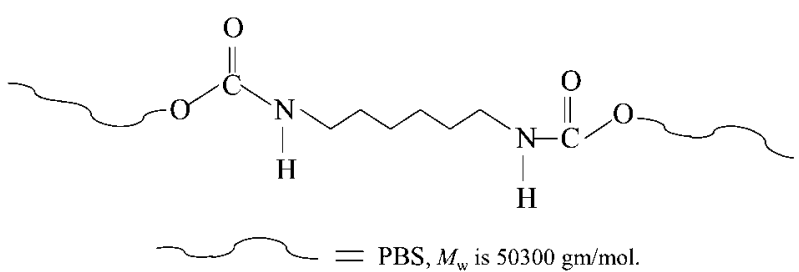

16 Formation of urethane bondings in high molecular weight PBS

hindered and only translational motion is available, and hence show very high modulus. This behaviour is clearly observed in dynamic storage modulus measurements under molten state. ${ }^{43}$ In the case of N6CN3.7 (MMT $=$ $3.7 \mathrm{wt}-\%)$ the same high increment in $G^{\prime}$ as well as PBSCNs can be seen. The development of the flocculated structure is occurred, even though N6CNs are well established exfoliated nanocomposite systems.

\section{Flow induced structure development}

\section{Steady shear flow}

The steady shear rheological behaviour of neat PBS and various PBSCNs are shown in Fig. 18. The steady viscosity of PBSCNs is enhanced considerably at all shear rates with time, and increases monotonically with increasing silicate loading at a fixed shear rate. ${ }^{44}$ On the other hand, all intercalated PBSCNs exhibit strong rheopexy behaviour, and this becomes prominent at low shear rates, while neat PBS exhibits a time independent viscosity at all shear rates. With increasing shear rates, the shear viscosity attains plateau after certain time, and the time required to attain this plateau decreases with increasing shear rates. The possible reasons for this type of behaviour may be due to the planer alignment of the clay particles towards the flow direction under shear. When the shear rate is very slow $\left(0.001 \mathrm{~s}^{-1}\right)$, clay particles take longer time to attain complete planer alignment along the flow direction, and this measurement time $(1000 \mathrm{~s})$ is too short to attain such alignment and hence show strong rheopexy behaviour. On the other hand, at high shear rates $\left(0.005\right.$ or $\left.0.01 \mathrm{~s}^{-1}\right)$ this measurement time is considerable enough to attain such alignment, and hence, nanocomposites show time independent shear viscosity after certain time.

Figure 19 shows shear rates dependence of viscosity for neat PBS and corresponding nanocomposites measured at $120^{\circ} \mathrm{C}$. While the neat PBS exhibits almost Newtonian behaviour at all shear rates, whereas

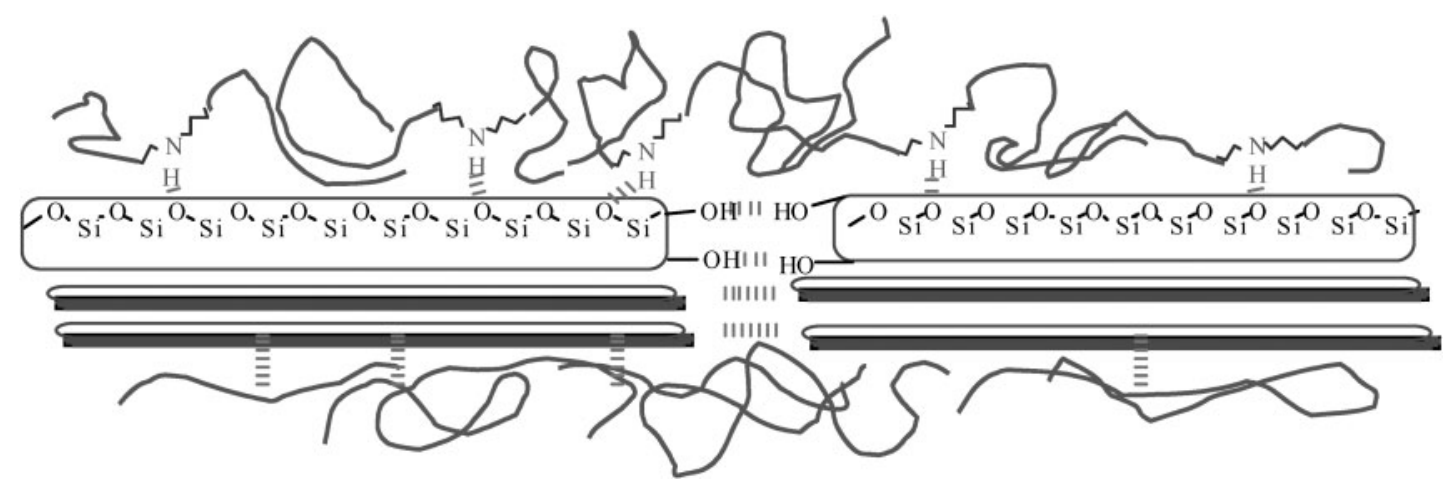

17 Formation of hydrogen bonds between PBS and clay, which leads to flocculation of dispersed silicate layers. Reprinted with permission from Ref. 43, ๑ 2003, American Chemical Society 


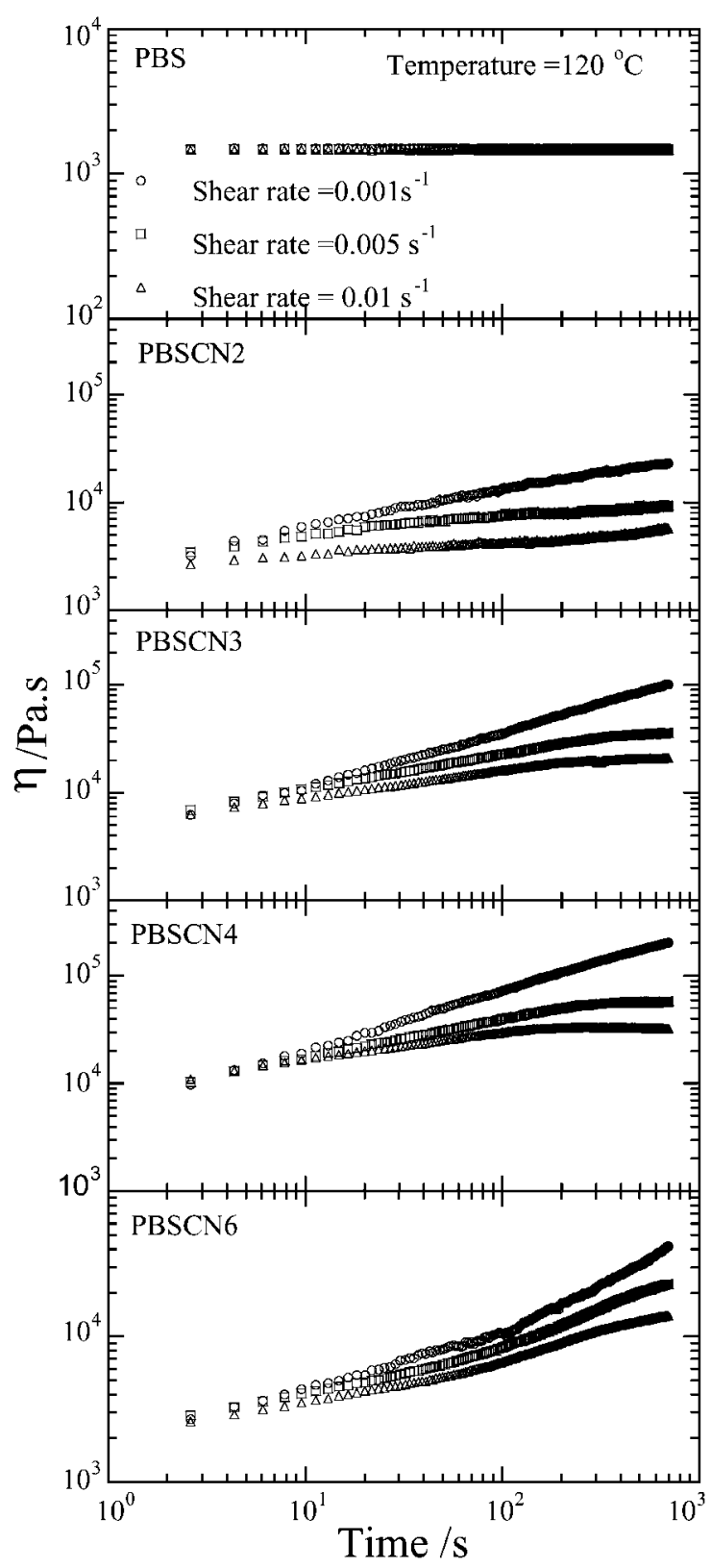

18 Time variation of shear viscosity for PBSCN. Reprinted with permission from Ref. 43, ๑ 2003, American Chemical Society

nanocomposite exhibits non-Newtonian behaviour. At very low shear rates, shear viscosity of nanocomposites initially exhibits some shear thickening behaviour and this is corresponding to the rheopexy behaviour observed at very low shear rates (see Fig. 18). After that all nanocomposites show very strong shear thinning behaviour at all shear rates and this behaviour is analogous to the results obtained in the case of dynamic oscillatory shear measurements. ${ }^{41}$ Additionally, at very high shear rates, the viscosities of nanocomposites are comparable with that of neat PBS. These observations suggest that the silicate layers are strongly oriented towards the flow direction at high shear rates, and shear thinning behaviour at high shear rates dominated by that of neat polymer.

The PLSNC melts always exhibit significant deviation from Cox-Merz relation, ${ }^{46}$ while all neat polymers nicely obey the empirical Cox-Merz relation, which requires that for $\dot{\gamma}=\omega$, the viscoelastic data should obey the

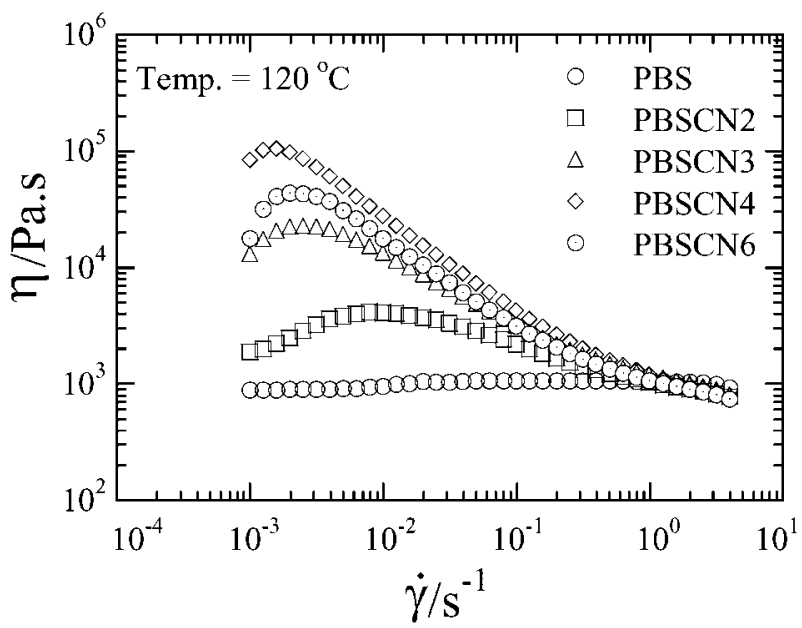

19 Shear viscosity as function of shear rates for shear rate sweep test. Reprinted with permission from Ref. 43, ㄷ 2003, American Chemical Society

relationship $\eta(\dot{\gamma})=\left|\eta^{*}\right|(\omega)$. It is believed that there are two possible reasons for the deviation of Cox-Merz relation in the case of nanocomposites. First of all, this rule is only applicable for homogenous systems like homopolymer melts, but nanocomposites are heterogeneous systems. For this reasons this relation is nicely obeyed in the case of neat polymer. ${ }^{43}$ Second, the structure formation is different when nanocomposites are subjected to dynamic oscillatory shear and steady shear measurements.

Okamoto et al. ${ }^{47}$ constructed unique rheo-optical device, angle light scattering apparatus (Rheo-SALS), which enables the authors to perform time resolved measurements of light intensity scattered from the internal structure developed under shear flow. Figure 20 shows a schematic illustration of the apparatus: plane polarised light normal to the $x$ axis (flow direction) was applied vertically to the parallel plate type shear cell along the velocity gradient ( $y$ axis). Scattering profiles were observed either under $\mathrm{Vv}$ mode (depolarised geometry in which the optical axis of the analyser was set parallel to that of the polariser) or Hv (the crosspolarised geometry with the two axes being set perpendicular to two axes) optical alignment at azimuthal angle $\mu$ of $0^{\circ}$. They reported the time variation of the mean square density fluctuation $\left\langle\eta^{2}\right\rangle$, the mean square anisotropy $<\delta^{2}>$ and the relevant value of correlation distance $\left(\xi_{\eta}\right.$ and $\left.\xi_{\delta}\right)$ upon imposition/cessation of steady shear flow at both low shear rate $\dot{\gamma}\left(\cong 0.5 \mathrm{~s}^{-1}\right)$ and high shear rate $\dot{\gamma}\left(\cong 60 \mathrm{~s}^{-1}\right)$.

\section{Elongational flow and strain induced hardening}

Okamoto et al. ${ }^{48}$ first conducted elongation test of PP/ LS nanocomposites (PPCN4) under molten state at constant Hencky strain rate, $\dot{\varepsilon}_{0}$ using an elongation flow optorheometry ${ }^{49}$ and also they attempted to control the alignment of the dispersed silicate layers with nanometre dimensions of an intercalated PPCNs under uniaxial elongational flow.

Figure 21 shows double logarithmic plots of transient elongational viscosity $\eta_{\mathrm{E}}\left(\dot{\varepsilon}_{0} ; t\right)$ against time $t$ observed for nylon 6/LS system (N6CN3.7) and PPCN4 (MMT= $4 \mathrm{wt}-\%)$ with different Hencky strain rates $\dot{\varepsilon}_{0}$ ranging from $0 \cdot 001$ to $1 \cdot 0 \mathrm{~s}^{-1}$. The solid curve represents time development of threefold shear viscosity $3 \eta_{0}(\dot{\gamma} ; t)$ at 

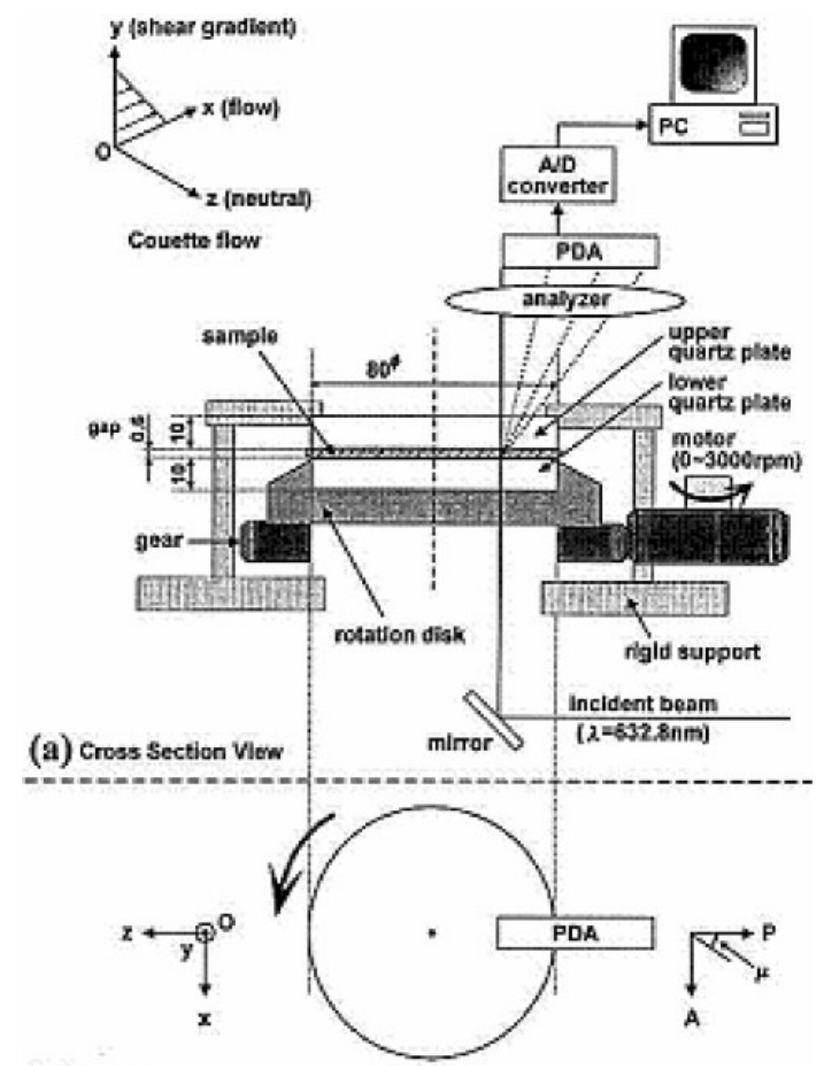

(b) Top Vlaw

\section{a cross-sectional; $b$ top views}

20 Schematic illustration of Rheo-SALS apparatus. Reprinted with permission from Ref. 47, () 2000, The Society of Rheology, Japan

$225^{\circ} \mathrm{C}$ with a constant shear rate $\dot{\gamma}=0.001 \mathrm{~s}^{-1}$. In $\eta_{\mathrm{E}}\left(\dot{\varepsilon}_{0} ; t\right)$ at any $\dot{\varepsilon}_{0}, \mathrm{~N} 6 \mathrm{CN} 3 \cdot 7$ melt shows a weak tendency of strain induced hardening as compared with that of PPCN4 melt. A strong behaviour of strain induced hardening for PPCN4 melt was originated from the perpendicular alignment of the silicate layers to the stretching direction as reported by Okamoto et al. ${ }^{48}$

From TEM observation (see Fig. 9), the N6CN3.7 forms a fine dispersion of the silicate layers of $\sim 100 \mathrm{~nm}$ in $L_{\text {clay }}, 3 \mathrm{~nm}$ thickness in $d_{\text {clay }}$ and $\xi_{\text {clay }}$ of about 20 $30 \mathrm{~nm}$ between them. The $\xi_{\text {clay }}$ value is a one order of magnitude lower than the value of $L_{\text {clay }}$, suggesting the formation of spatially linked like structure of the dispersed clay particles in nylon 6 matrix. For N6CN3.7 melt, the silicate layers are so densely dispersed into the matrix and hence difficult to align under elongational flow. Under flow fields, the silicate layers might translationally move, but not rotationally in such a way that the loss energy becomes minimum. This tendency was also observed in PPCN7.5 melt with higher content of MMT $=7 \cdot 5 \mathrm{wt}-\%{ }^{50}$

On the other hand, two features for the shear viscosity curve can be observed. First, the extended Trouton rule $3 \eta_{0}(\dot{\gamma} ; t) \cong \eta_{\mathrm{E}}\left(\dot{\varepsilon}_{0} ; t\right)$ does not hold for both N6CN3.7 and PPCN4 melts, as opposed to the melt of ordinary homopolymers. The latter $\eta_{E}\left(\dot{\varepsilon}_{0} ; t\right)$ is more than 10 times larger than the former $3 \eta_{0}(\dot{\gamma} ; t)$. Second, again unlike ordinary polymer melts, $3 \eta_{0}(\dot{\gamma} ; t)$ of $\mathrm{N} 6 \mathrm{CN} 3 \cdot 7$ melt increases continuously with $t$, never showing a tendency of reaching a steady state within the time span $(600 \mathrm{~s}$ or

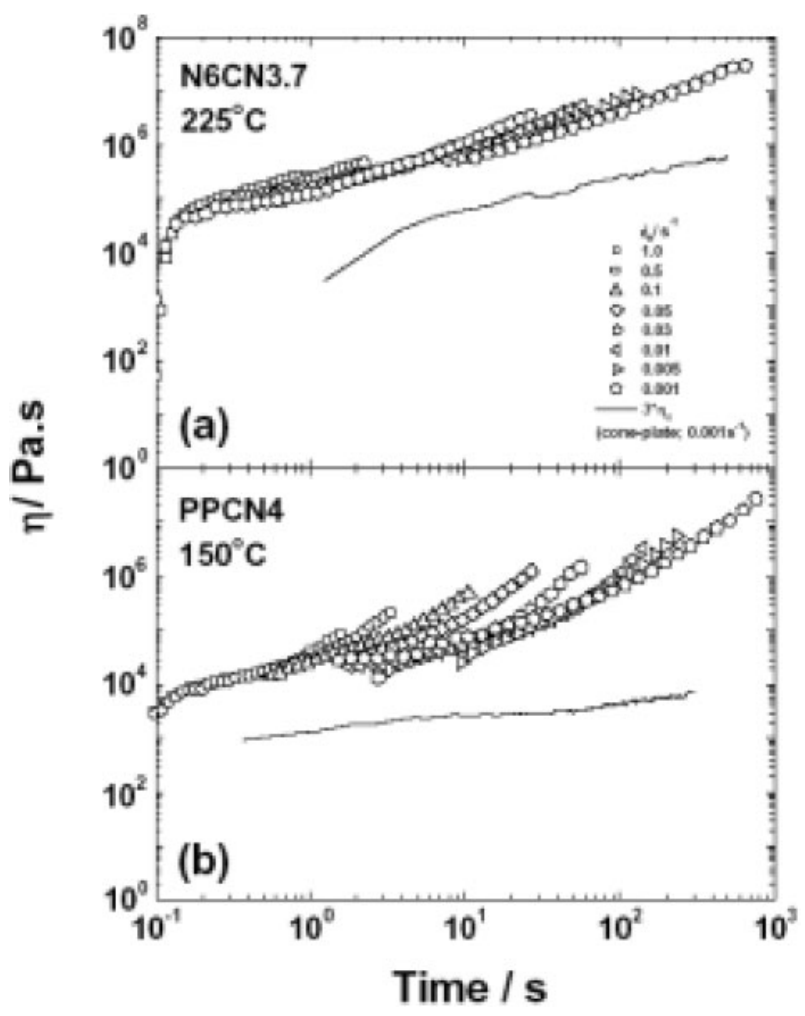

21 Time variation of elongational viscosity $\eta_{\mathrm{E}}\left(\dot{\varepsilon}_{0} ; t\right)$ for a N6CN3.7 melt at $225^{\circ} \mathrm{C}$ and for $b$ PPCN4 at $150^{\circ} \mathrm{C}$ : solid line shows three times shear viscosity $3 \eta_{0}\left(\dot{\gamma}_{0} ; t\right)$, taken at low shear rate $\dot{\gamma}=0.001 \mathrm{~s}^{-1}$ on cone plate rheometer. Reprinted with permission from Ref. 2, (c) 2003, Rapra Technology Ltd

longer) examined here. This time dependent thickening behaviour may be called antithixotropy or rheopexy. At slow shear flow $\left(\dot{\gamma}=0.001 \mathrm{~s}^{-1}\right), 3 \eta_{0}(\dot{\gamma} ; t)$ of N6CN3.7 exhibits a much stronger rheopexy behaviour with almost two order of magnitude higher than that of PPCN4. This reflects a fact that the shear induced structural change involved a process with an extremely long relaxation time as well as for other PLSNCs with rheopexy behaviour, ${ }^{43}$ especially under weak shear field.

\section{Alignment of silicate layers}

The orientation of silicate layers and nylon 6 crystallites in injection moulded $\mathrm{N} 6 \mathrm{CN}$ is examined using WAXD and TEM. ${ }^{51,52}$ Kojima and his colleagues have found three regions of different orientations in the sample as a function of depth. Near the middle of the sample, where the shear forces are minimal, the silicate layers are oriented randomly and the nylon 6 crystallites are perpendicular to the silicate layers. In the surface region, shear stresses are very high, and therefore both the clay layers and the nylon 6 crystallites are parallel to the surface. In the intermediate region, the clay layers, presumably owing to their higher aspect ratio, still orient parallel to the surface and the nylon 6 crystallites assume an orientation perpendicular to the silicate. Very recently, Medellin-Rodriguez et al. ${ }^{53}$ reported that the molten N6CN samples showed planar orientation of silicate layers along the flow direction, which is strongly dependent on shear time as well as clay loading, reaching a maximally orienting level after being sheared for $15 \mathrm{~min}$ with $\dot{\gamma}=60 \mathrm{~s}^{-1}$. 


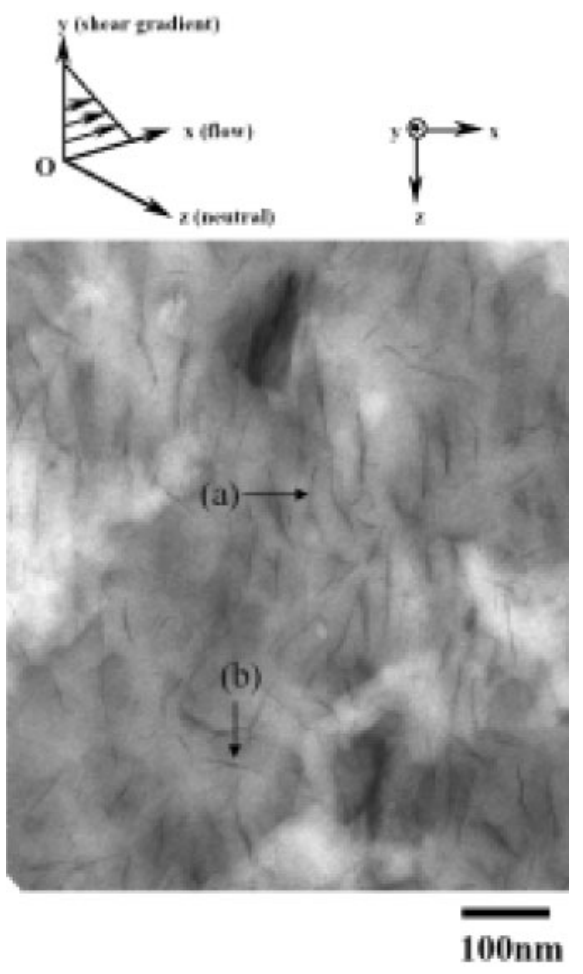

22 Micrograph (TEM) in $x-z$ plane showing N6CN3.7 sheared at $225^{\circ} \mathrm{C}$ with $\dot{\gamma}=0.0006 \mathrm{~s}^{-1}$ for $1000 \mathrm{~s}$ : $x, y$ and $z$ axes correspond to flow, shear gradient and neutral direction respectively. Reprinted with permission from Ref. 2, () 2003, Rapra Technology Ltd

Okamoto and his colleagues conducted the TEM observation for the sheared N6CN3.7 with $\dot{\gamma}=$ $0.0006 \mathrm{~s}^{-1}$ for $1000 \mathrm{~s}$ (Ref. 2). The edges of the silicate layers laying along the $z$ axis (marked with the arrow (a)) or parallel alignment of the silicate edges to the shear direction ( $x$ axis) (marked with the arrow (b)) rather than assumingly random orientation in the nylon 6 matrix is observed, but in fact, these faces in this plane can be seen (Fig. 22). Here, it should be emphasised that the planar orientation of the silicate faces along the $x-z$ plane does not take place prominently. For the case of rapid shear flow, the commonly applicable conjecture of the planar orientation of the silicate faces along the shear direction first demonstrated to be true by Kojima and his colleagues. 51

In uniaxial elongational flow (converging low) for a PPCN4, the formation of a house of cards structure is found by TEM analysis. ${ }^{48}$ The perpendicular (but not parallel) alignment of disk like clay particles with large anisotropy towards the flow direction might sound unlikely, but this could be the case especially under an elongational flow field, in which the extentional flow rate is the square of the converging flow rate along the thickness direction, if the assumption of affine deformation without volume change is valid. Obviously under such conditions, energy dissipation rate owing to viscous resistance between the disk surface and the matrix polymer is minimal, when the disks are aligned perpendicular to the flow direction.

Moreover, Lele and his colleagues ${ }^{54}$ recently reported the in situ Rheo X-ray investigation of flow induced orientation in syndiotactic PP/layered silicate nanocomposite melt.

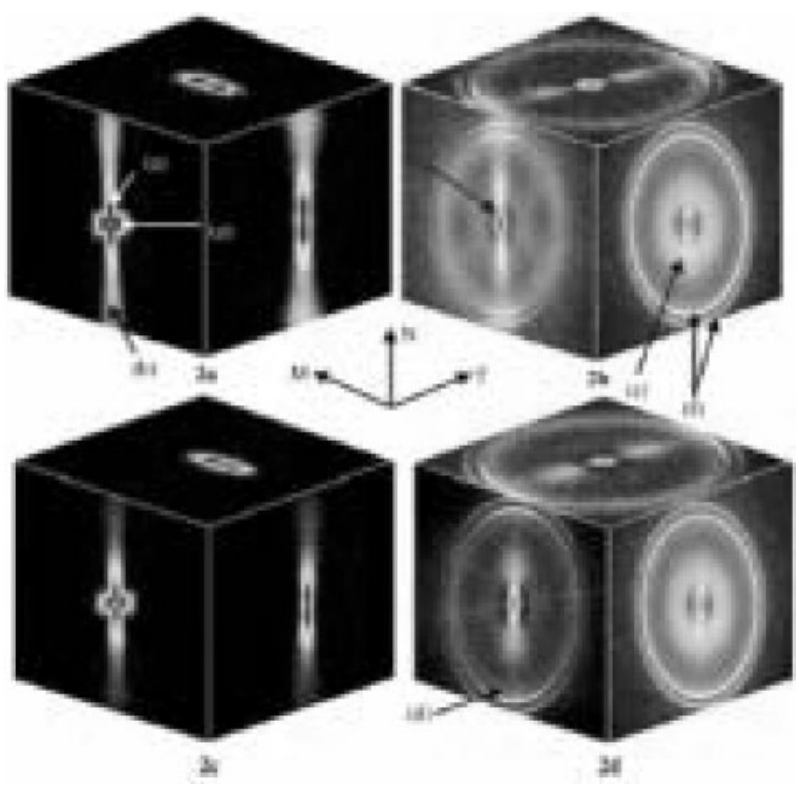

23 2D SAXS (a and c) and WAXS (b and d) patterns for orientation MN (left face), NT (right face) and MT (top face) of films HD603 (a and b) and HD612 (c and d): numbers in parentheses represent reflections from following: (a) clay tactoids, (b) modified/intercalated clay (002) plane, (c) unmodified clay (002) plane, (d) clay (110) and (020) plane, (e) polymer crystalline lamellar, (f) polymer unit cell (110) plane (inner ring) and (200) plane (outer ring). Reprinted with permission from Ref. 55, $\odot$ 2003, Elsevier Science

Very recently, Bafna et al. ${ }^{55}$ developed a technique to determine the three-dimensional (3D) orientation of various hierarchical organic and inorganic structures in a PLSNCs. They studied the effect of compatibiliser concentration on the orientation of various structures in PLSNCs using two-dimensional (2D) SAXS and 2D WAXD in three sample/camera orientations. Reflections and orientation of six different structural features were easily identified:

(i) clay clusters/tactoids $(0 \cdot 12 \mu \mathrm{m})$

(ii) modified/intercalated clay stacking period (002) $(2 \cdot 4-3 \cdot 1 \mathrm{~nm})$

(iii) stacking period of unmodified clay platelets (002) $(1 \cdot 3 \mathrm{~nm})$

(iv) clay (110) and (020) planes, normal (ii) and (iii)

(v) polymer crystalline lamellae (001) $(19-26 \mathrm{~nm})$, long period $((001)$ is an average crystallographic direction)

(vi) polymer unit cell (110) and (200) planes.

The corresponding identified reflections are presented in Fig. 23. A 3D study of the relative orientation of the above mentioned structures was carried out by measuring three projections of each sample. Quantitative data on the orientation of these structural units in the nanocomposite film were determined through calculations of the major axis direction cosines and through a ternary, direction cosine plot called a 'Wilchinsky triangle', ${ }^{56}$ previously proposed in lamellar orientation studies. ${ }^{57}$ It allows a direct comparison of average preferred orientations for different structural features. In this way it is conceptually more useful than stereographic projections involving orientation density maps for a single WAXD reflection. 
About 20 years ago, van Olphen ${ }^{19}$ pointed out that the electrostatic attraction between the layers of natural clay in aqueous suspension arises from higher polar force in the medium. The intriguing features such as yield stress thixotropy and/or rheopexy exhibited in aqueous suspensions of natural clay minerals may be taken as a reference to the present PLSNCs.

\section{Electrorheology}

Electrorheological fluids (ERFs), sometimes referred to as 'smart fluids', are suspensions consisting of polarisable particles dispersed in insulating media. A mismatch in conductivity or dielectric constant between the dispersed particle and the continuous medium phase induces polarisation upon application of an electric filed. The induced particle dipoles under the action of an electric field tend to attract neighbouring particles and cause the particles to form fibril like structures, which are aligned to the electric field direction.

Among various materials, ${ }^{58-61}$ semiconducting polymers are one of the novel intrinsic ER systems, because it has the advantage of a wide range of working temperature, reduced abrasion of device, low cost and relatively low current density. As a result, development of a high performance ERF followed by conducting polymer optimisation and tuning has been the subject of considerable interest for practical applications as a new electromechanic interface. Nevertheless, the yield stress and modulus of ERFs are lower than those of magnetorheological fluids. Therefore, the performance of conducting polymer based ERFs is still insufficient for the successful development of specific application devices.

On this basis of this information's, Kim et al. ${ }^{58}$ first introduced nanocomposite as ERFs using polyaniline (PANI)/LS nanocomposites with intercalated structure. Although PANI/clay intercalated nanocomposites are a new material for application of ER materials, yield stresses of the system showed less than $100 \mathrm{~Pa}$ at $1 \cdot 2 \mathrm{kV} \mathrm{mm}^{-1}$ (20 wt- $\%$ suspensions). This value is a little lower than the yield stress of pure PANI particle system. ${ }^{59}$ In other words, no synergistic effect of clay on yield stress was shown.

Recently, Park and his colleagues ${ }^{60}$ have observed remarkable enhancement of yield stress for ERFs in PANI based nanocomposites of clay. In their further study ${ }^{61}$, they fabricated three kinds of ERFs containing different contents of PANI/clay nanocomposite and pure PANI particles in order to investigate the effect of nanocomposite particles on the enhancement of yield stress more systematically. They observed that there is an optimum content ratio between nanocomposite and pure PANI particles to produce minimum yield stress. Details regarding data collection and explanations are presented. $^{61}$

\section{Processing operations}

The flow induced internal structural change occurs in both shear and elongational flow, but almost differs from each other, as judged from the above results on $\eta_{E}\left(\dot{\varepsilon}_{0} ; t\right)$ and $3 \eta_{0}(\dot{\gamma} ; t)$ (see Fig. 21). Therefore, with these rheological features of the PCNs and the characteristics of each processing operation, which process type should be selected for a particular nanocomposite for the enhancement of its mechanical properties?
For example, the strong strain induced hardening in $\eta_{E}\left(\dot{\varepsilon}_{0} ; t\right)$ is requisite for withstanding the stretching force during the processing, while the rheopexy in $3 \eta_{0}(\dot{\gamma} ; t)$ suggests that for such PLSNC a promising technology is the processing in confined space such the injection moulding where shear force is crucial.

\section{Foam processing using $\mathrm{SC}-\mathrm{CO}_{2}$}

Very recently, the first successful nanocomposite foam, processed by $\mathrm{sc}-\mathrm{CO}_{2}$ as a physical foaming agent, appeared through a pioneering effort by Okamoto and his colleagues. ${ }^{6,63}$

Figure 24 shows the typical results of SEM images of the fracture surfaces of the intercalated polycarbonate (PC)/layered silicate nanocomposites (PCCNs) and PC/ SMA blend (matrix) without clay foamed at $160^{\circ} \mathrm{C}$ under different isobaric saturation conditions of $\mathrm{sc}-\mathrm{CO}_{2}$ $(10,14$ and $18 \mathrm{MPa}) .{ }^{64}$ PC/SMA foams exhibit the polygon closed cell structures with pentagonal and hexagonal faces, which express the most energetically stable state of polygon cells. Such foam structure was obtained probably because these foams belong to the polymeric foams with high gas phase volume $(>0 \cdot 6){ }^{65}$ Obviously, under low saturation $\mathrm{CO}_{2}$ pressure ( $\sim 10 \mathrm{MPa})$, both PCCN foams exhibit large cell size, indicating the dispersed clay particles hinder $\mathrm{CO}_{2}$ diffusion by creating a maze or a more tortuous path as discussed in the literatures. ${ }^{2}$ However, a high $\mathrm{CO}_{2}$ pressure $(\sim 18 \mathrm{MPa})$ provides a large supply of $\mathrm{CO}_{2}$ molecules, which can subsequently form a large population of cell nuclei upon depressurisation. The PC/SMA/ MAE1 $\left(2 \mathrm{C}_{1} 2 \mathrm{C}_{18}\right.$-fluorohectrite) (including organoclay of $1 \mathrm{wt}-\%$ ) foam shows smaller cell size, i.e. larger cell density compared with PC/SMA foam, suggesting that the dispersed clay particles act as nucleating sites for cell formation and lowering of $d$ with clay. The incorporation of nanoclay hinder $\mathrm{CO}_{2}$ diffusion and simultaneously induce heterogeneous nucleation because of a lower activation energy barrier compared with homogeneous nucleation. ${ }^{66}$ They conducted the characterisation of the interfacial tension between bubble and matrix by modified classical nucleation theory. ${ }^{66}$

In Table 4, the interfacial tension of the systems is summarised. ${ }^{67}$ It can be seen that PC/SMA system has a slightly large value $\left(17 \cdot 3 \mathrm{~mJ} \mathrm{~m}^{-2}\right)$ compared with that of PC/SMA/MAE1 (14.6 $\left.\mathrm{mJ} \mathrm{m}^{-2}\right)$ and PC/SMA/MTE1 $\left(\mathrm{C}_{1} 3 \mathrm{C}_{8}\right.$-fluorohectrite $)\left(16.0 \mathrm{~mJ} \mathrm{~m}{ }^{-2}\right)$ in the case of a low $\mathrm{CO}_{2}$ pressure $(10 \mathrm{MPa})$. These estimated values of $\gamma$ are in good agreement with that of other poly(methylmethacrylate) (PMMA)- $\mathrm{CO}_{2}$ system $\left(10-20 \mathrm{~mJ} \mathrm{~m}^{-2}\right){ }^{68}$ The value for PC/SMA system decreases with increasing $\mathrm{CO}_{2}$ pressure, as expected, while PC/SMA/MAE1 shows a constant value with increasing pressure. This trend reflects the relative importance of heterogeneous

Table 4 Interfacial tension of systems calculated using Suh and Colton's theory

\begin{tabular}{lll}
\hline System & $\boldsymbol{P}_{\mathrm{CO}_{2}}, \mathbf{M P a}$ & $\boldsymbol{\gamma}, \mathbf{m J ~ m}^{-\mathbf{2}}$ \\
\hline PC/SMA-CO & 10 & $17 \cdot 3$ \\
PC/SMA/MAE-CO & 10 & $14 \cdot 6$ \\
PC/SMA/MTE-CO & 10 & $16 \cdot 0$ \\
\hline
\end{tabular}

MAE: dimethyl dioctadecyl ammonium cation modified synthetic fluorohectorite; MTE: methyl trioctil ammonium cation modified synthetic fluorohectorite. 


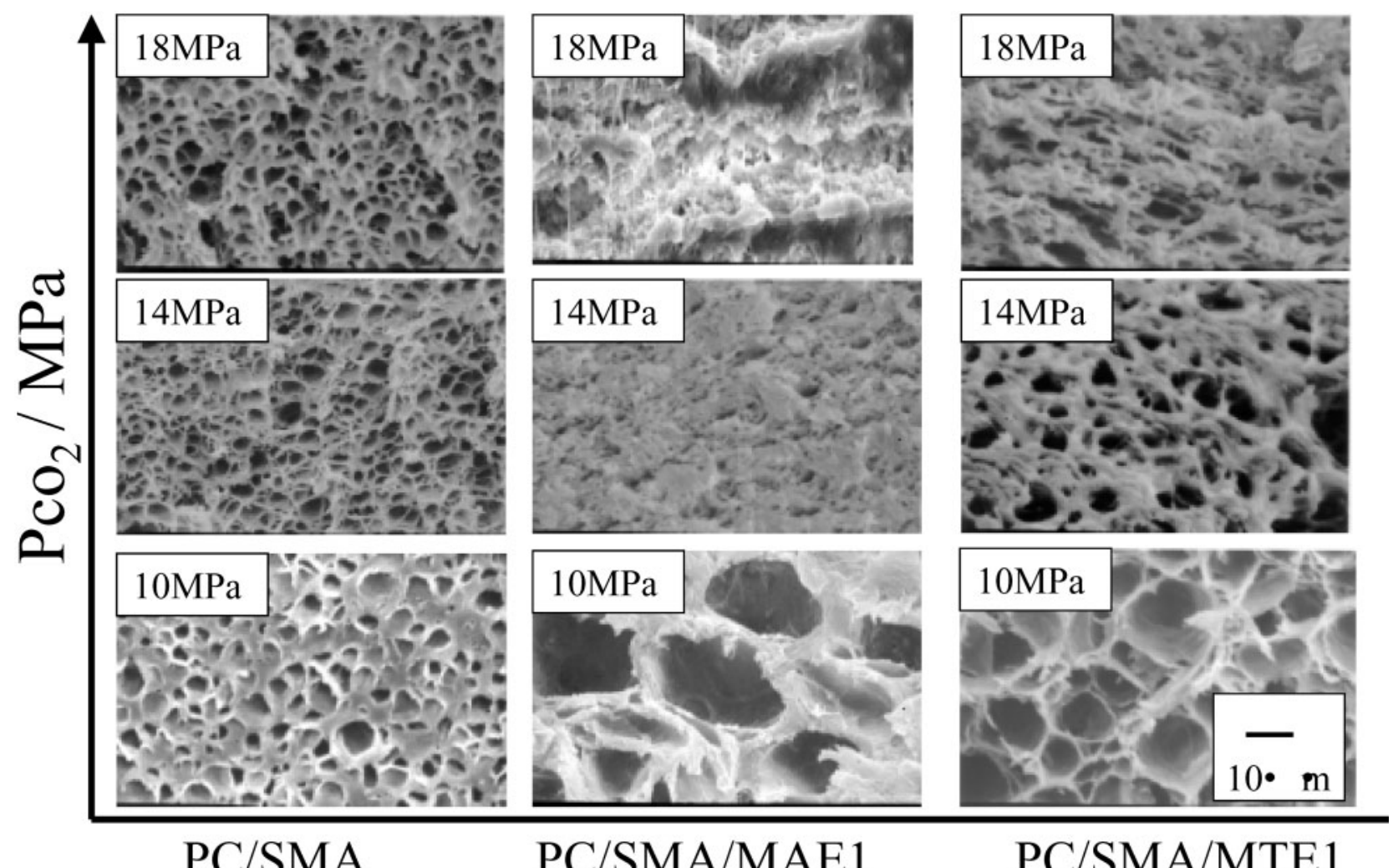

24 Typical SEM images of fracture surfaces of PCCNs and PC/SMA blend without clay foamed at $160^{\circ} \mathrm{C}$ under different isobaric conditions (10, 14 and $18 \mathrm{MPa}$ )

nucleation, which dominates over homogeneous one in the event that the amount of $\mathrm{CO}_{2}$ available for bubble nucleation is limited.

Figure 25 shows the stress-strain curves and the strain recovery behaviour of the PPCN foams ${ }^{62}$ in the compression mode at a constant strain rate of $5 \% \mathrm{~min}^{-1}$. The nanocomposite foams exhibit high modulus compared with neat PP-MA foam. The residual strain is $17 \%$ for PPCN2 (including $2 \mathrm{wt}-\%$ of organoclay) as well as neat PP foam, providing the excellent strain recovery and the energy dissipation mechanism, probably with the house of cards structure formation in the cell wall, ${ }^{62}$ which enhance the mechanical properties of the nanocomposites like a spruce wood which is close to right handed helix (see Fig. 26). ${ }^{63}$

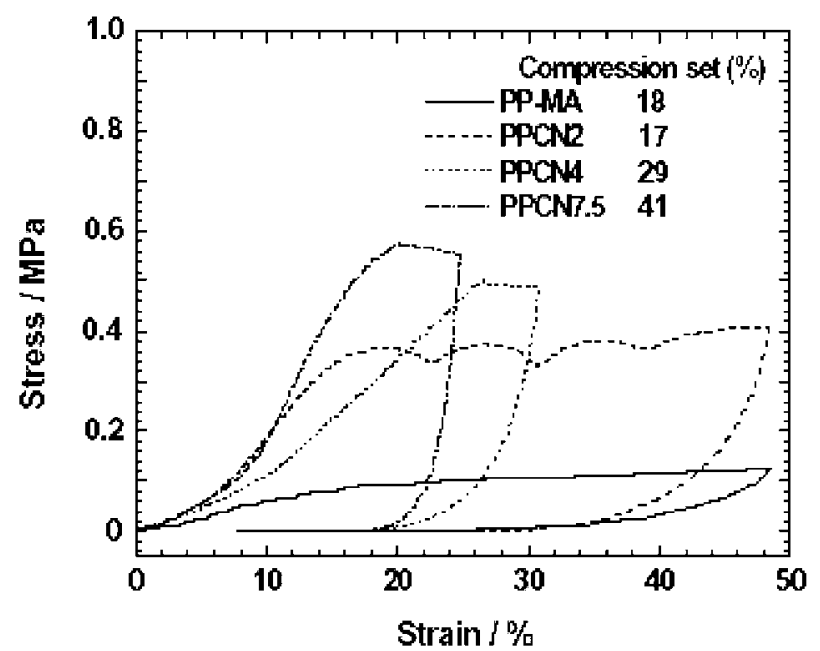

25 Stress-strain curves and strain recovery behaviour of PPCNs
Figure 27 shows the relationship among the cell size $d$, the cell density $N_{\mathrm{c}}$ and the mean cell wall thickness $\delta$ of the nanocomposite foams obtained by a series of their recent studies. ${ }^{64,69}$ In the case of nanocomposite foams, the cell wall thickness becomes 2-6 times compared with that of neat polymer foams owing to the spherical cell shape $^{63}$ caused by the high modulus of the materials during processing. The controlled structure of the nanocomposite foams changes from microcellular $(d \cong 20 \mu \mathrm{m}$ and $N_{\mathrm{c}} \cong 1 \cdot 0 \times 10^{9}$ cell $\left.\mathrm{cm}^{-3}\right)$ to nanocellular $(d \cong 200 \mathrm{~nm}$ and $N_{\mathrm{c}} \cong 1 \cdot 0 \times 10^{14}$ cell $\mathrm{cm}^{-3}$ ).

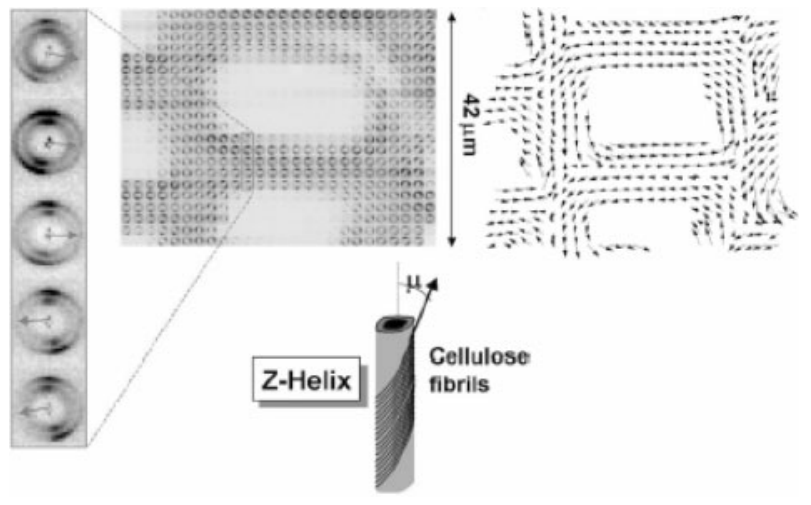

26 X-ray microdiffraction experiment with $2 \mu \mathrm{m}$ thick section of spruce wood embedded in resin: note asymmetry of patterns in enlargement (far left) which can be used to determine local orientation of cellulose fibrils in cell wall (arrows); arrows are plotted in right image with convention that they represent projection of vector parallel to fibrils onto plane of crosssection; picture clearly shows that all cells are right handed helices. Reprinted with permission from Ref. 63, ๑ 2003, Elsevier Science 

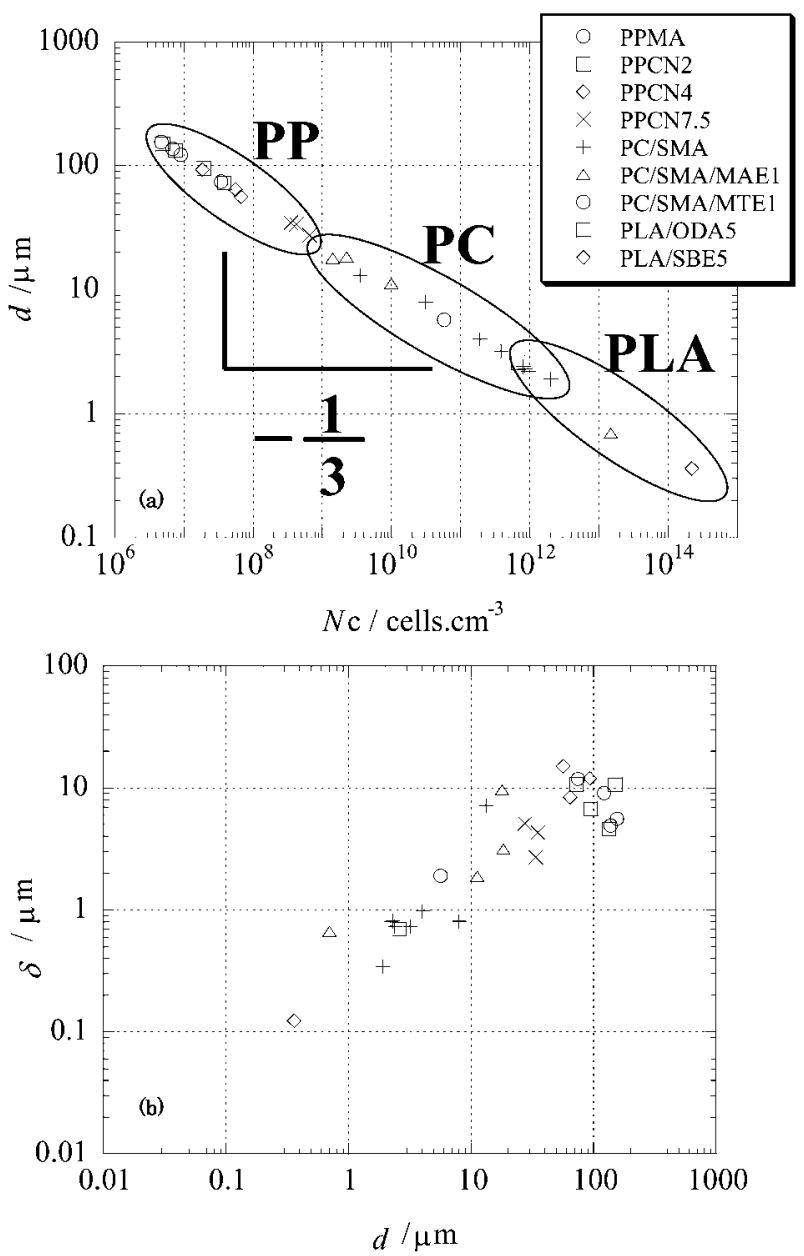

$27 a$ cell size versus cell density and $b$ cell wall thickness $\delta$ versus cell size for PCCN systems: for comparison, here it is shown other nanocomposite foams obtained by series of recent studies; ${ }^{64,69} \mathrm{PP}$ : polypropylene based, PLA: polylactide based nanocomposite foams

Recently, some literature has also been available $\mathrm{e}^{70-73}$ related to the reactive extrusion foaming of various nanocomposites.

\section{Electrospining processing}

Fibres and nanofibres of N6CN (diameter of 100$500 \mathrm{~nm}$ ) were electrospun from 1,1,1,3,3,3-hexafluoro-2propanole (HFIP) solution and collected as non-woven fabrics or as aligned yarns. $^{74}$ The electrospinning process resulted in highly aligned MMT particles and nylon 6 crystallites. The cylindrical shaped fibres and nanofibres, ribbon shaped fibres were also found in the products (Fig. 28). The electrospinning can be expected to align other nanofillers such as carbon nanotubes.

\section{Porous ceramic materials via PLSNCs}

Very recently, a new route for the preparation of porous ceramic material from thermosetting epoxy/clay nanocomposite was first demonstrated by Brown et al. ${ }^{75}$ This route offers attractive potential for diversification and application of the PPCNs. Ray and co-workers have reported the results on the novel porous ceramic material via burning of the PLA/LS system (PLACN) which contains 3.0 wt- $\%$ inorganic clay. ${ }^{76}$ The SEM image of fracture surface of porous ceramic material

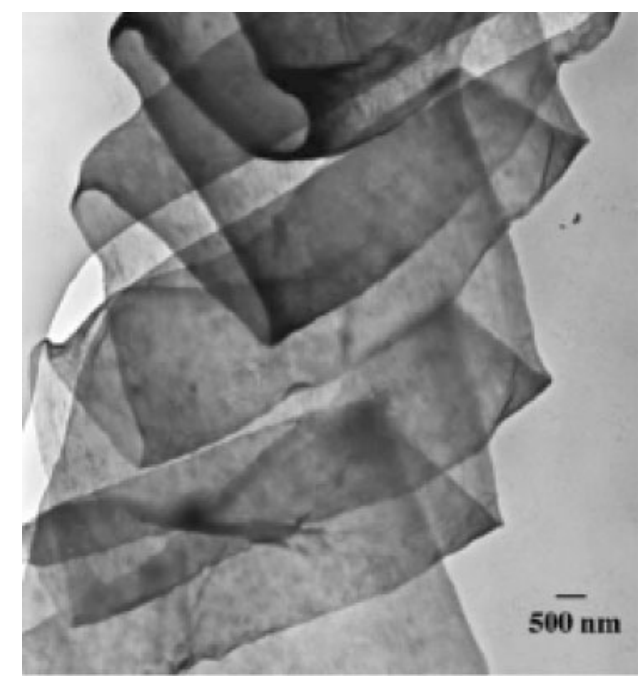

28 Micrograph (TEM) of ribbon shaped nanofibre. Reprinted with permission from Ref. 74, ( 2002, Elsevier Science

prepared from simple burning of the PLACN in a furnace up to $950^{\circ} \mathrm{C}$ is shown in Fig. 29. After complete burning, as seen in Fig. 29, the PLACN becomes white mass with porous structure. The bright lines in the SEM image correspond to the edge of the stacked silicate layers. In the porous ceramic material, the silicate layers form a cards house structure, which consist of the large plates with length of $\sim 1000 \mathrm{~nm}$ and thickness of about 30-60 nm. This implies that the further stacked platelet structure is formed during burning. The material exhibits the open cell type structure with 100-1000 nm diameter void, the BET surface area of $31 \mathrm{~m}^{2} \mathrm{~g}^{-1}$ and a low density of porous material of $0.187 \mathrm{~g} \mathrm{~mL}^{-1}$ estimated by the buoyancy method. The BET surface area value of MMT is $780 \mathrm{~m}^{2} \mathrm{~g}^{-1}$ and that of the porous ceramic material is $31 \mathrm{~m}^{2} \mathrm{~g}^{-1}$, suggesting that $\sim 25$ MMT plates were stacked together. When MMT is heated $>700^{\circ} \mathrm{C}$ (but $<960^{\circ} \mathrm{C}$ ), first all $\mathrm{OH}$ groups are eliminated from the structure, and thus MMT is decomposed into that of a non-hydrated aluminosilicate. This transformation radically disturbs the crystalline network of the MMT, and resulting diffraction pattern

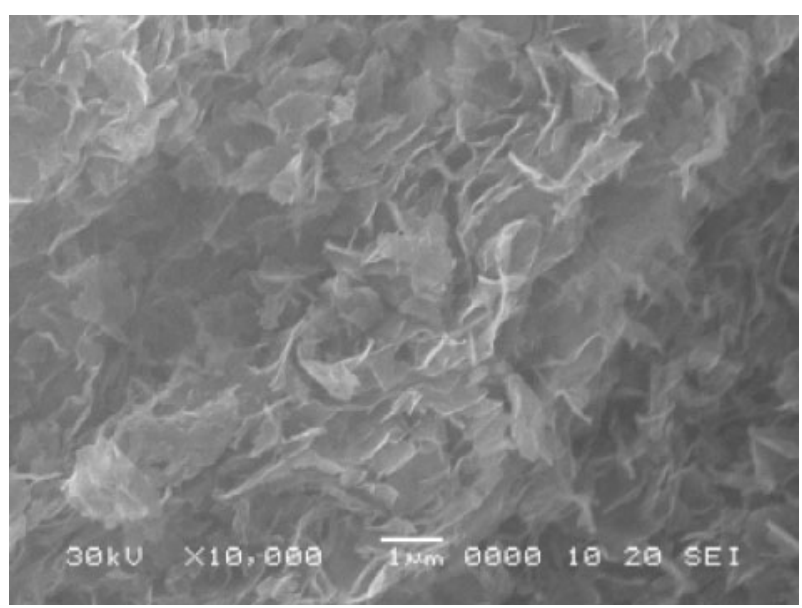

29 Image (SEM) of porous ceramic material after coated with platinum layer $(\sim \mathbf{1 0} \mathrm{nm}$ thickness). Reprinted with permission from Ref. 76, ๑ 2002, American Chemical Society 
is indeed often typical of an amorphous (or noncrystalline) phase. The estimated rough value of compression modulus $K$ is in the order of $\sim 1.2 \mathrm{MPa}$, which is five orders of magnitude lower than the bulk modulus of MMT $\left(\sim 10^{2} \mathrm{GPa}\right){ }^{2}$ In the stress-strain curve, the linear deformation behaviour is nicely described in the early stage of the deformation, i.e. the deformation of the material closely resembles that of ordinary polymeric foams. ${ }^{77}$ This open cell type porous ceramic material consisting of the cards house structure is expected to provide the strain recovery and excellent energy dissipation mechanism after unloading in the elastic region up to $8 \%$ strain, probably each plate bend like leaf spring. This porous ceramic material is a new material possessing feature of elastic and very lightweight. This new route for the preparation of porous ceramic material via burning of nanocomposites can be expected to pave the way for much broader range of applications of the PLSNCs. This porous ceramic material closely relates an excellent insulator property for flame reterdant of PLSNCs. ${ }^{2}$ The flame behaviour must derive from the morphological control of the shielding properties of the graphitic/clay created during polymer ablation.

\section{Physicochemical phenomena \\ Biodegradability}

Another most interesting and exciting aspect of nanocomposite technology is the significant improvements of biodegradability of biodegradable polymers after nanocomposites preparation with organoclay. Aliphatic polyesters are among the most promising materials for the production of environmentally friendly biodegradable plastics. Biodegradation of aliphatic polyester is well known, in that some bacteria degrade them by producing enzymes, which attack the polymer. Tetto and his colleagues ${ }^{78}$ first reported some results about the biodegradability of nanocomposites based on PCL, in which the authors found that the poly( $\varepsilon$-caprolactone) (PCL)/LS nanocomposites showed improved biodegradability compared with pure PCL. According to them, the improved biodegradability of PCL after nanocomposites formation may be due to the catalytic role of the organoclay in the biodegradation mechanism. However, still it is unclear how the clay increases the biodegradation rate of PCL.

Recently, Lee et al. $^{79}$ reported the biodegradation of aliphatic polyester based nanocomposites under compost. Figure $30 a$ and $b$ represents the clay content dependence of biodegradation of aliphatic polyester (APES) based nanocomposites prepared with two different types of clays respectively. It is assumed that the retardation of biodegradation owing to the improvement of the barrier properties of the aliphatic APSE after nanocomposites preparation with clay. However, there are no data about permeability.

Very recently, Yamada and Okamoto et al. ${ }^{80-83}$ first reported the biodegradability of neat PLA and corresponding nanocomposites prepared with trimethyl octadecylammonium modified MMT $\left(3 \mathrm{C}_{1} \mathrm{C}_{18}\right.$-MMT) with details mechanism. The used compost was prepared from food waste, and tests were carried out at a temperature of $58 \pm 2^{\circ} \mathrm{C}$. Figure $31 a$ shows the real picture of the recovered samples of neat PLA and
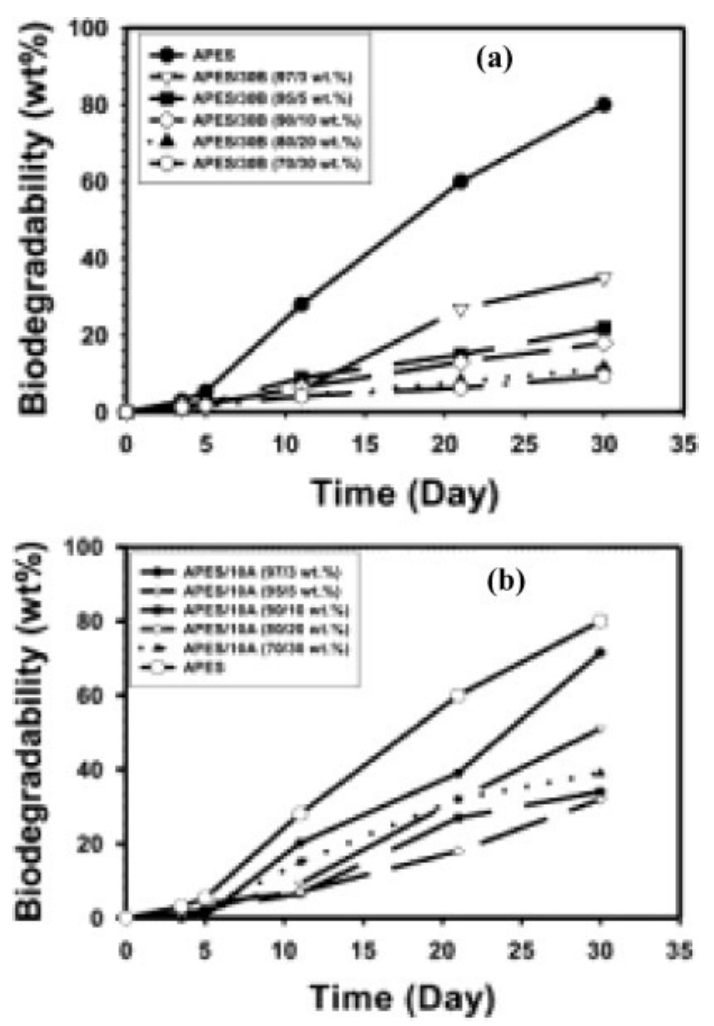

30 Biodegradability of APES nanocomposites with a Closite 30B and $b$ Closite 10A. Reprinted with permission from Ref. 79, ๔ 2002, Elsevier Science

PLACN4 $\left(3 \mathrm{C}_{1} \mathrm{C}_{18}-\mathrm{MMT}=4 \mathrm{wt} \%\right)$ from compost with time. The decreased molecular weight $M_{\mathrm{w}}$ and residual weight percentage $R_{\mathrm{w}}$ of the initial test samples with time were also reported in Figure $31 b$. The biodegradability of neat PLA is significantly enhanced after PLSNC preparation. Within one month, both extent of $M_{\mathrm{w}}$ and extent of weight loss are almost the same level for both PLA and PLACN4. However, after one month, a sharp change occurs in weight loss of PLACN4, and within two months, it is completely degrade in compost. The degradation of PLA in compost is a complex process involving four main phenomena, namely

(i) water absorption

(ii) ester cleavage and formation of oligomer fragments

(iii) solubilisation of oligomer fragments

(iv) diffusion of soluble oligomers by bacteria. ${ }^{84}$

Therefore, the factor, which increases the hydrolysis tendency of PLA, ultimately controls the degradation of PLA. It is expected that the presence of terminal hydroxylated edge groups of the silicate layers may be one of the responsible factors for this behaviour. In the case of PLACN4, the stacked (about four layers) and intercalated silicate layers are homogeneously dispersed in the PLA matrix (from TEM image) ${ }^{82}$, and these hydroxy groups start heterogeneous hydrolysis of the PLA matrix after absorbing water from compost. It takes some time to start this process. For this reason, the weight loss and degree of hydrolysis of PLA and PLACN4 are almost the same up to one month (see Fig. $31 b$ ). However, after one month, there is a sharp weight loss in the case of PLACN4 compared with that of PLA. That means one month is a critical value to start heterogeneous hydrolysis, and owing to this type of hydrolysis matrix becomes very small fragments and 
(a)

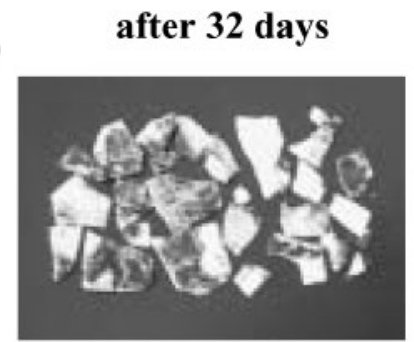

after 50 days

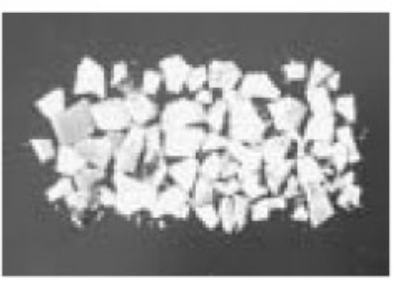

after 60 days

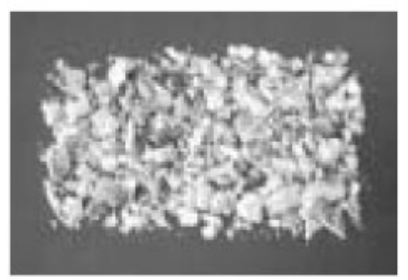

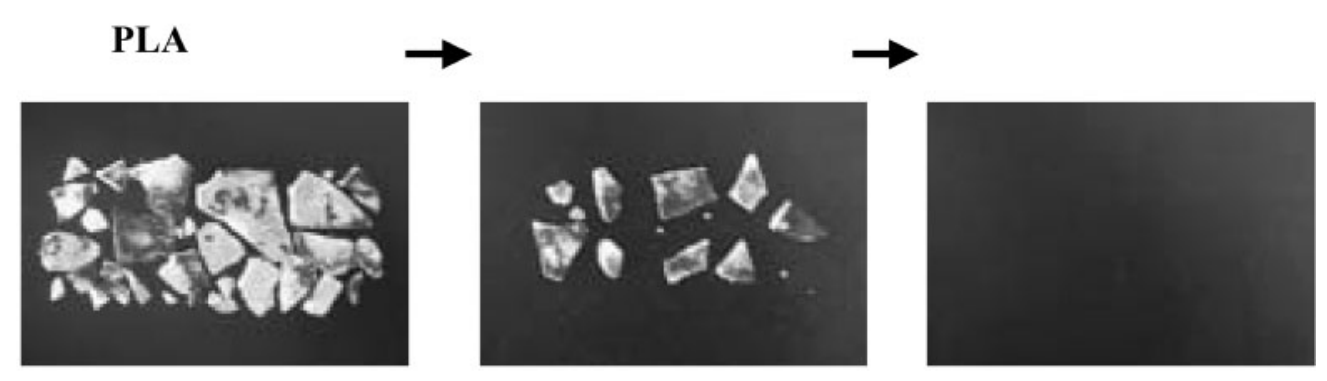

\section{PLACN4}

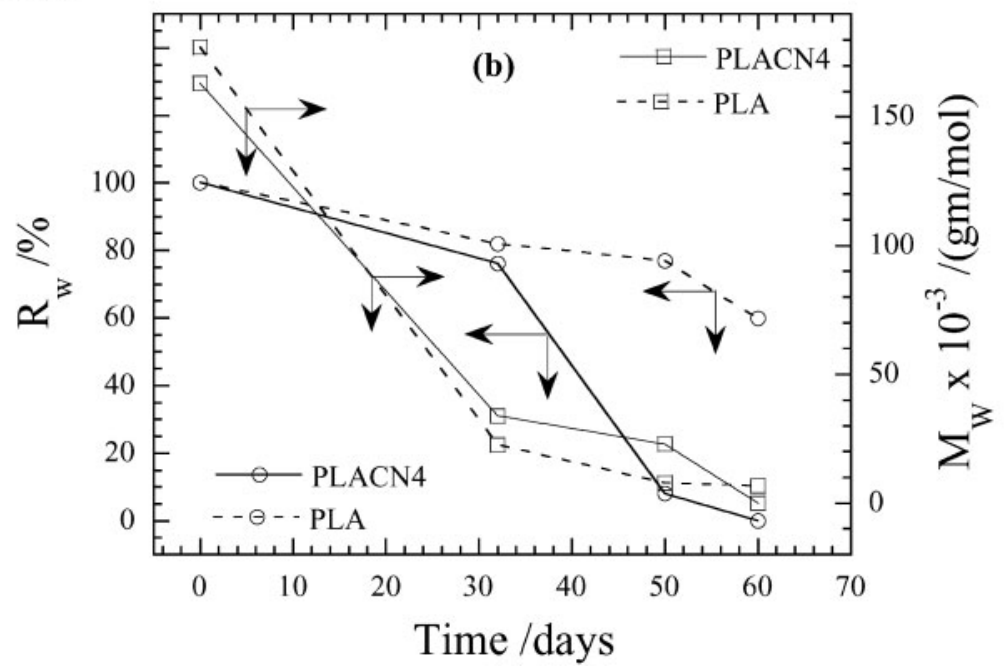

31 a real picture of biodegradability of neat PLA and PLACN4 recovered from compost with time: nitial shape of crystallised samples was $3 \times 10 \times 0.1 \mathrm{~cm}^{3}$ and $b$ time dependence of residual weight $R_{\mathrm{w}}$ and of matrix $M_{\mathrm{w}}$ of $\mathrm{PLA}$ and PLACN4 under compost at $58 \pm 2$ C. Reprinted with permission from Ref. 80, ( 2002, American Chemical Society

disappears with compost. This assumption was confirmed by conducting the same type of experiment with PLACN prepared by dimethyl dioctdecyl ammonium salt modified synthetic mica which has no terminal hydroxylated edge group, and the degradation tendency almost the same with neat PLA. ${ }^{81}$

They also conducted respirometric test to study degradation of the PLA matrix in compost environment at $58 \pm 2{ }^{\circ} \mathrm{C}$. For this test the used compost was made from bean curd refuse, food waste and cattle feces. Unlike weight loss, which reflects the structural changes in the test sample, $\mathrm{CO}_{2}$ evolution provides an indicator of the ultimate biodegradability of PLA in PLACN4 (prepared with ( $N($ cocoalkyl) $N, N$-[bis(2-hydroxyethyl)]$N$-methylammonium modified synthetic mica,), i.e. mineralisation, of the samples. Figure 32 shows the time dependence of the degree of biodegradation of neat PLA and PLACN4, indicating that the biodegradability of PLA in PLACN4 is enhanced significantly. The presence of organoclay may thus cause a different mode of attack on the PLA component, which might be due to the presence of hydroxy groups. Details of the mechanism of biodegradability are presented in relevant literature. ${ }^{81,82}$
K. Okamoto and M. Okamoto also investigated biodegradability of neat PBS before and after nanocomposites preparation with three different types of organoclay. They used alkylammonium or alkylphosphonium salts for the modification of pristine layered silicates, and these surfactants were toxic for microorganisms. ${ }^{43,85}$

Figure $33 a$ shows the real pictures of recovered samples of neat PBS and various nanocomposites from the compost after 35 days. From Fig. 33, it is clearly observed that many cracks appeared in nanocomposite samples compared with that of neat PBS. This observation indicates the improved degradability of nanocomposites in compost. This kind of fracture has an advantage for biodegradation because of easy to mix with compost and to create much more surface area for further attack by micro-organisms, and it should be noted here that the extent of fragmentation is directly related to the nature of organoclay used for nanocomposites preparation. They also conducted the gel permeation chromatography (GPC) measurement of recovered samples from compost, and it can be found that the extent of molecular weight loss is almost the 

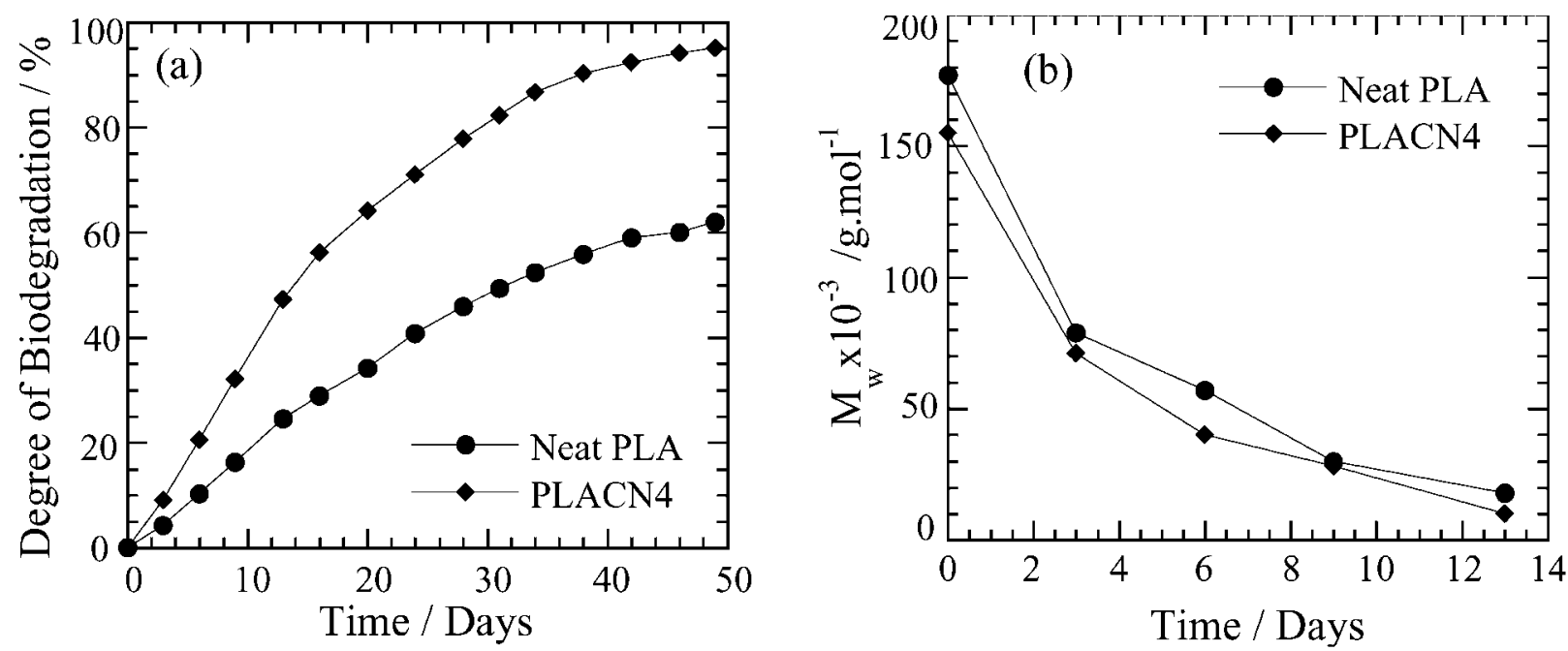

32 a degree of biodegradation (i.e. $\mathrm{CO}_{2}$ evolution) and $b$ time dependent change of matrix $\boldsymbol{M}_{\mathrm{w}}$ of neat PLA and PLACN4 (MEE clay $=4 \mathrm{wt}-\%$ ) under compost at $58 \pm 2^{\circ} \mathrm{C}$. Reprinted with permission from Ref. 81, $\odot 2004$, WILEY-VCH Verlag GmbH \& Co

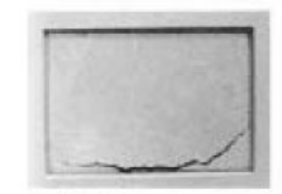

PBS

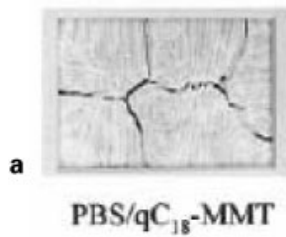

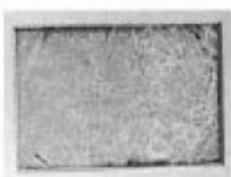

$\mathrm{PBS} / \mathrm{C}_{18}-\mathrm{MMT}$

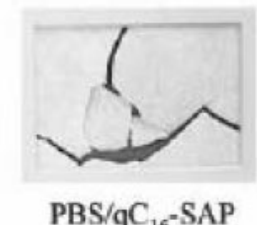

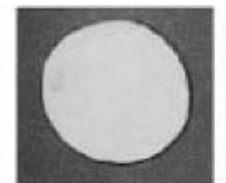

PBS

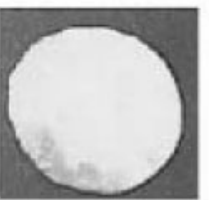

$\mathrm{PBS} / \mathrm{qC} \mathrm{C}_{18}-\mathrm{MMT}$

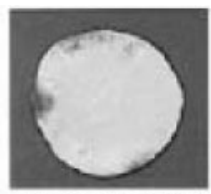

$\mathrm{PBS} / \mathrm{C}_{18}-\mathrm{MMT}$

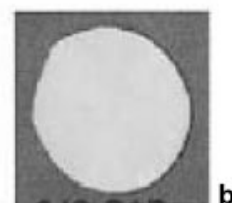

PBS/qC $16-\mathrm{SAP}$

33 Biodegradability of neat PBS and various nanocomposites sheets $a$ under compost and $b$ under soil field. Reprinted with permission from Ref. 85, $\odot$ 2003, John Wiley \& Sons

same for all samples (see Table 5). This result indicates that the extent of hydrolysis of PBS in pure state or organically modified layered silicate (OMLS) filled systems is the same in compost.

Except for the PBS/qC 16 -SAP ( $n$-hexadecyl tri-n-butyl phosphonium cation modified saponite) system, the degree of degradation is not different for other samples. This observation indicates that MMT or alkylammonium cations, and other properties have no effect on the biodegradability of PBS at the same time. The accelerated degradation of PBS matrix in the presence of $\mathrm{qC}_{16^{-}}$ SAP may be due to the presence of alkylphosphonium surfactant. This kind of behaviour is also observed in the case of PLA/LS nanocomposite systems.

They also observed the nature of degradation of PBS and various nanocomposites under soil field. The present experiment was conducted for one, two and six months. After one and two months, there is no change on the nature of surface of the samples, but after six months black or red spots appeared on the surface of nanocomposites samples. Figure $33 b$ represents the results of degradation of neat PBS and various nanocomposites sheets recovered from soil field after six months. It is reported that these spots on the sample surface are due to the fungus attacked, because when these parts were put into the slurry and a clear growth of fungus was observed. These results also indicate that nanocomposites exhibit the same or higher level of biodegradability compared with PBS matrix.

\section{Photodegradation}

Very recently, Hiroi and Okamoto et al. ${ }^{86}$ first reported the photodegradability of neat PLA and corresponding

Table 5 Results of various samples recovered from compost after 35 days with GPC measurement

\begin{tabular}{|c|c|c|c|c|}
\hline Samples & $M_{\mathrm{w}}, \times 10^{-3} \mathrm{~g} \mathrm{~mol}^{-1}$ & $M_{\mathrm{n}}, \times 10^{-3} \mathrm{~g} \mathrm{~mol}^{-1}$ & $M_{\mathrm{w}}^{\circ *}, \times 10^{-3} \mathrm{~g} \mathrm{~mol}^{-1}$ & $M_{\mathrm{w}} / M_{\mathrm{w}}^{\circ}$ \\
\hline PBS & 16 & $3 \cdot 8$ & 101 & $0 \cdot 16$ \\
\hline $\mathrm{PBS} / \mathrm{C}_{18}-\mathrm{MMT}$ & 17 & $6 \cdot 6$ & 104 & $0 \cdot 16$ \\
\hline $\mathrm{PBS} / \mathrm{qC}_{18}-\mathrm{MMT}$ & 17 & $4 \cdot 4$ & 112 & $0 \cdot 15$ \\
\hline PBS/qC $16-S A P$ & $8 \cdot 7$ & $1 \cdot 2$ & 91 & 0.096 \\
\hline
\end{tabular}

*Molecular weight before composting. 


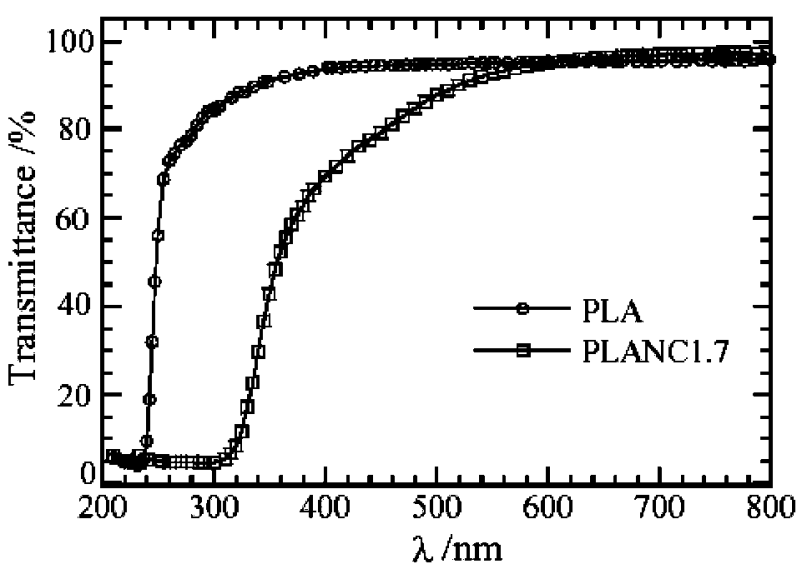

34 UV/VIS transmission spectra of neat PLA and nanocomposite (PLANC1-7). Reprinted with permission from Ref. 86, ๔ 2004, WILEY-VCH Verlag GmbH \& Co

PLA nanocomposite prepared by organically modified layered titanate as a new nanofiller. One of the features of this material is photocatalytic reactivity, such as titania $\left(\mathrm{TiO}_{2}\right)$. The photocatalytic reaction of anatase$\mathrm{TiO}_{2}$, such as evolution of hydrogen gas from water or oxidative degradation of organic compounds, has attracted intense research interest because of their possible application to the conversion of solar energy into chemical energy. ${ }^{87}$

Figure 34 shows the UV/VIS transmission spectra of pure PLA and nanocomposite (PLANC1·7). The spectra show that the VIS region (larger than $\sim 400 \mathrm{~nm}$ ) is changed with increasing absorbency by the presence of titanate layers compared with neat PLA. For UV wavelengths, there is strong absorption up to $320 \mathrm{~nm}$, resulting in $0 \%$ transmittance. This significant change in the spectra may indicate that occurrence of the photodegradation of PLA matrix. To confirm this, they conducted some preliminary experiments on photodegradation of PLANCs under sunshine weathermeter at $60^{\circ} \mathrm{C}$. After $300 \mathrm{~h}$, there was no change in the nature of sample surfaces of neat PLA, however, the surface colour of nanocomposite samples altered yellow and/or light brown. Table 6 shows the GPC measurement of recovered samples from the test. The drop in $M_{\mathrm{w}}$ accompanied with broadening of $M_{\mathrm{w}} / M_{\mathrm{n}}$ indicates that the enhancement of degradation of PLA in the titanate filled system has occurred.

\section{Pressure volume temperature (PVT) behaviour}

Recently, in N6 based nanocomposites (N6CNs) the reduction in free volume by $12-17 \%$ was reported through a pioneering effort by Utracki et $a l^{88}$ Figure 35 shows the temperature dependence of the free volume reduction by the addition of nanoclay particles. It is speculated that the N6 chains are absorbed on the solid clay surface and the first few absorbed layers are

Table 6 Results of sample recovered from weathermeter after $300 \mathrm{~h}$ with GPC measurement ${ }^{86}$

\begin{tabular}{|c|c|c|c|}
\hline Samples & $M_{\mathrm{w}}, \times 10^{-3} \mathrm{~g} \mathrm{~mol}^{-1}$ & $M_{\mathrm{w}} / M_{\mathrm{n}}$ & $M_{\mathrm{w}} / M_{\mathrm{w}}^{\circ}$ \\
\hline PLA & 198 & 1.53 & 0.94 \\
\hline PLANC1.7 & $93 \cdot 7$ & $1 \cdot 89$ & 0.68 \\
\hline PLANC3.9 & $86 \cdot 3$ & $1 \cdot 86$ & 0.76 \\
\hline
\end{tabular}

$M_{\mathrm{w}}^{\circ}$ : molecular weight before test.

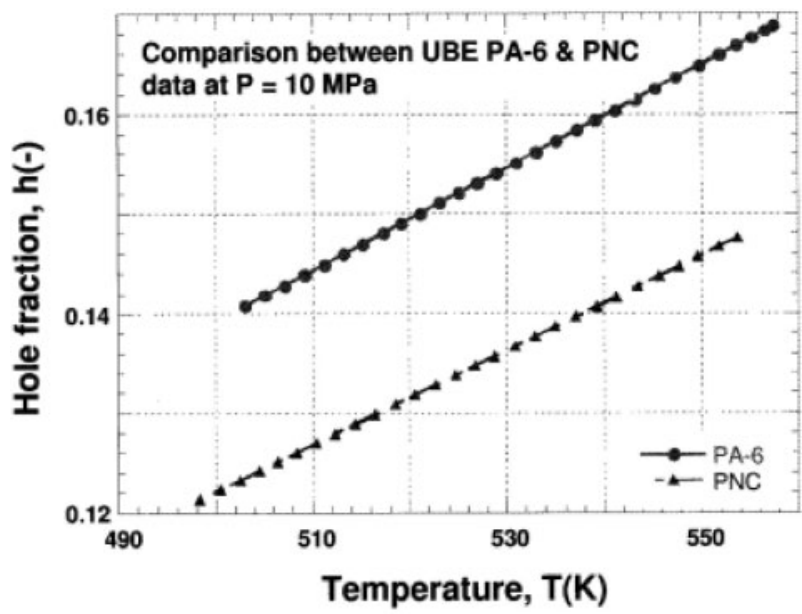

35 Hole fraction versus temperature for N6 based nanocompopsite. Reprinted with permission from Ref. 88, (c) 2001, VSP

immobilised. This loss of mobility translates in their model into a free volume loss. The effect was simulated by a large adhesion ratio $\varepsilon^{*}{ }_{12} / \varepsilon^{*}{ }_{11}\left(=313.54 \mathrm{~kJ} \mathrm{~mol}^{-1} /\right.$ $32.09 \mathrm{~kJ} \mathrm{~mol}^{-1}$ ), which is the energetic interaction parameter between polymer clay and polymer polymer. It is also reported the value of the free volume reduction for the polystyrene based nanocomposite system. ${ }^{89}$ In the case of $4 \mathrm{wt}-\%$ organoclay loading, the reducton is much lower (4-6\%) than that of N6 based nanocomposites owing to the weak interaction between polymer and silicate surfaces.

Recently, some literatures are also available ${ }^{90}$ related to the PVT dependencies of commercial PP melt and its nanocomposites including small amount of a compatibiliser. Another recent approach is positron annihilation lifetime spectroscopy for evaluation of the free volume fraction in PLSNCs. ${ }^{91}$

\section{Computer simulation}

\section{Theoretical phase diagram of PLSNCs}

Recently, Ginzburg and Balazs developed simple models that describe the liquid crystalline ordering in the polymer platelet systems. ${ }^{92-95}$ They combined a density functional theory (DFT) with a selfconsistent field (SCF) model to calculate the phase behaviour of thin, oblate colloidal particles that are coated with surfactants and dispersed in a polymer melt. These coated particles represent organoclay sheets. By intergrafting the two methods, they investigated the effect of the surfactants characteristics (grafting density $\rho_{\mathrm{gr}}$ and length $N_{\mathrm{gr}}$ ) and the polymer intercalant interaction energy on the polymer/clay phase diagram (see Fig. 36). ${ }^{93}$ Depending on the values of these critical parameters and clay volume fraction $\phi$, the system can be in an isotropic or nematic phase (exfoliated system). The system can also form a smectic, crystal, columnar, or house of cards plastic solid as well as a two phase immiscible mixture. Using this model they isolated conditions that lead to the stabilisation of the exfoliated nanocomposite system and to the narrowing of the immiscible two phase regions.

Furthermore, they extended their study to take end functionalised polymer chains into consideration. ${ }^{94}$ The parameter $\varepsilon$ characterises the interaction between 

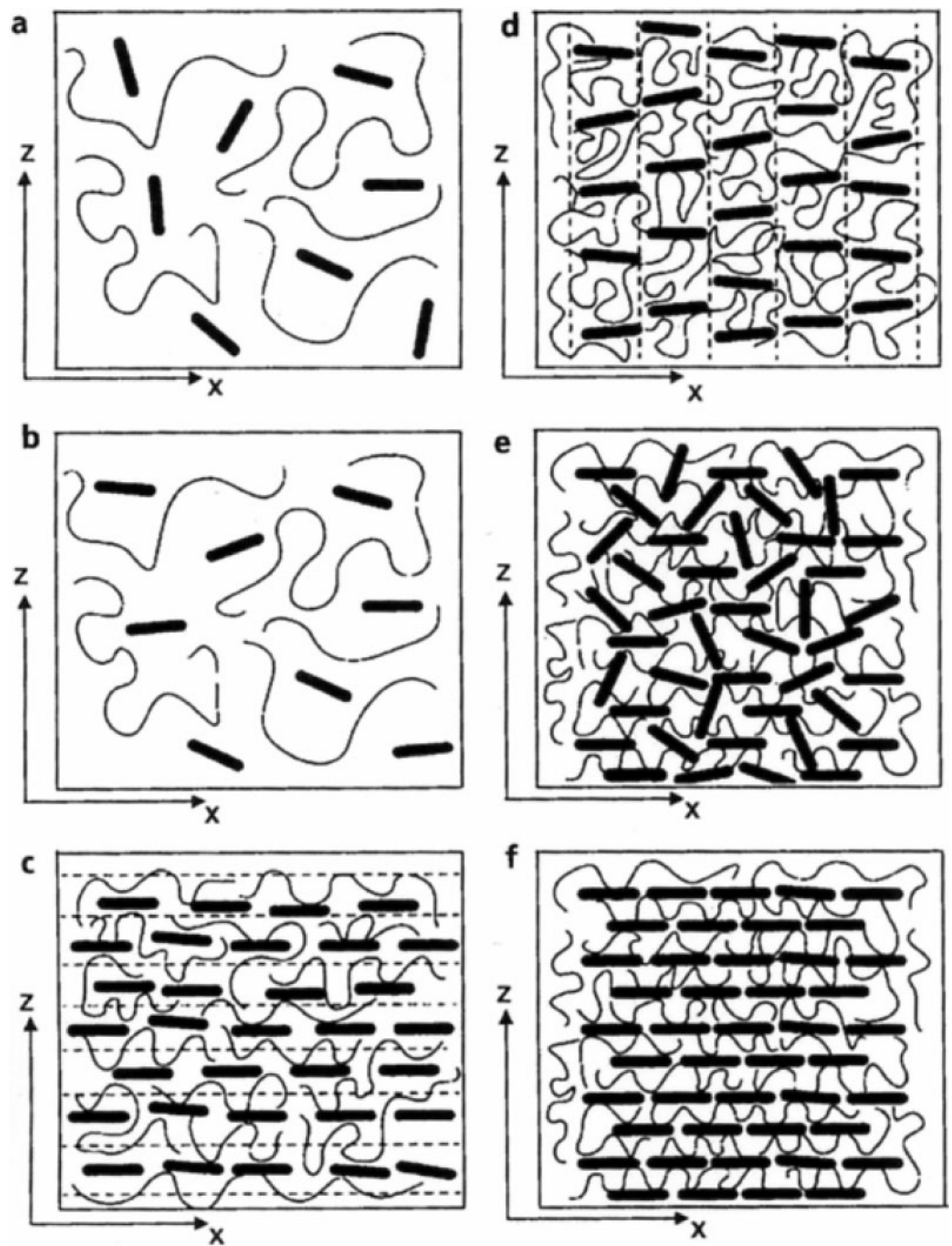

$a$ isotropic (I); $b$ nematic (N); c smectic (S); $d$ columnar (Col); e plastic solid (house of cards) (PS); $f$ crystal (Cr)

36 Mesophases of oblate uniaxial particles dispersed in polymer: nematic director $n$ in ordered phases is aligned along $Z$ axis, disks lie in XY plane; broken lines show smectic layers and columns. Reprinted with permission from Ref. 94, ๑ 2000, American Chemical Society

the terminal functional group and the surface. For small negative $\varepsilon$, the system is completely immiscible. As the sticker/surface attraction is increased, the system exhibits isotropic and nematic morphologies at relatively low clay volume fractions $(\phi<0 \cdot 12)$. The latter structures correspond to thermodynamically stable, exfoliated nanocomposite. Finally, when the surface/sticker attraction is increased even further, the system exhibits a plastic solid at low $\phi$, and a columnar phase at very high $\phi$ (see Fig. 37). The resulting phase diagrams can be used as guidelines for the nanocomposite formation with thermodynamically stable morphologies.

\section{Atomic scale structure and binding energy in PLSNCs}

Molecular simulation techniques are used to explore and characterise the atomic scale structure, and to predict binding energies and basal spacing of PLSNCs based on PP and PP-MA, MMT and different alkylammonium ions as intercalants. ${ }^{96}$ The basic machinery of the procedure consists in building a molecular model comprising PP, a given intercalant and MMT, refining and equilibrating it by molecular mechanics/molecular dynamics (MM/MD), and calculating the binding energies as guidelines for screening among different 


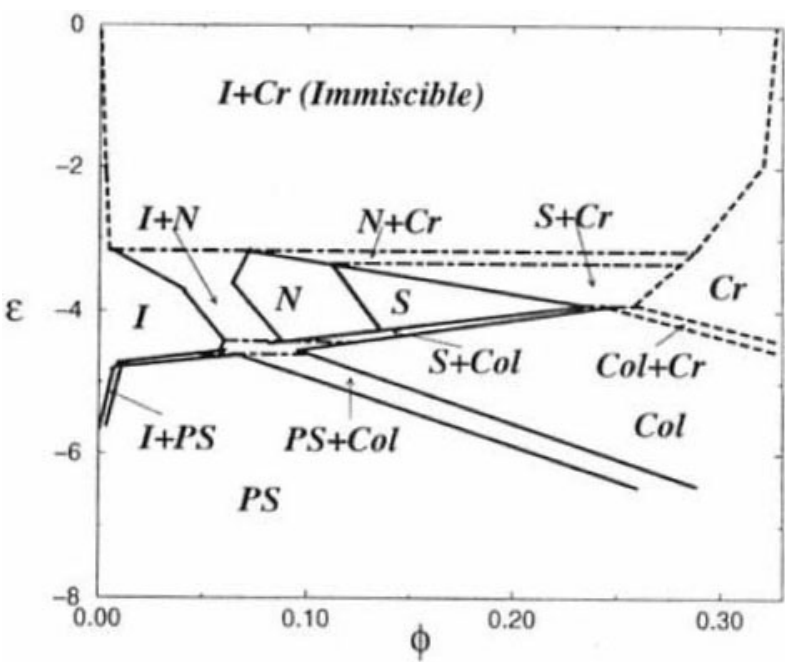

37 Phase diagram for polymer/clay mixture: here $\varepsilon$ is sticker clay adhesion energy. Reprinted with permission from Ref. 94, ๑ 2000, WILEY-VCH Verlag GmbH \& Co

intercalants to make PLSNCs characterised by strong interface between dispersed clay platelets and the PP matrix (see Fig. 38). Figure 39 shows the predicted binding energy versus volume of the intercalant. From a global interpretation of all these molecular dynamics simulation results, it can be concluded that intercalants with smaller volume are more effective for clay modification as they improve the thermodynamics of the system by increasing the binding energy, while on the other hand intercalants with longer tails are more effective for intercalation and exfoliation processes, as they lead to higher basal spacing. Alike, for a given surfactant molecule, the use of PP-MA in the preparation of PLSNCs results in a system with the most favourable interaction energy but with a lower basal spacing. Under the hypothesis, the MMT platelets are
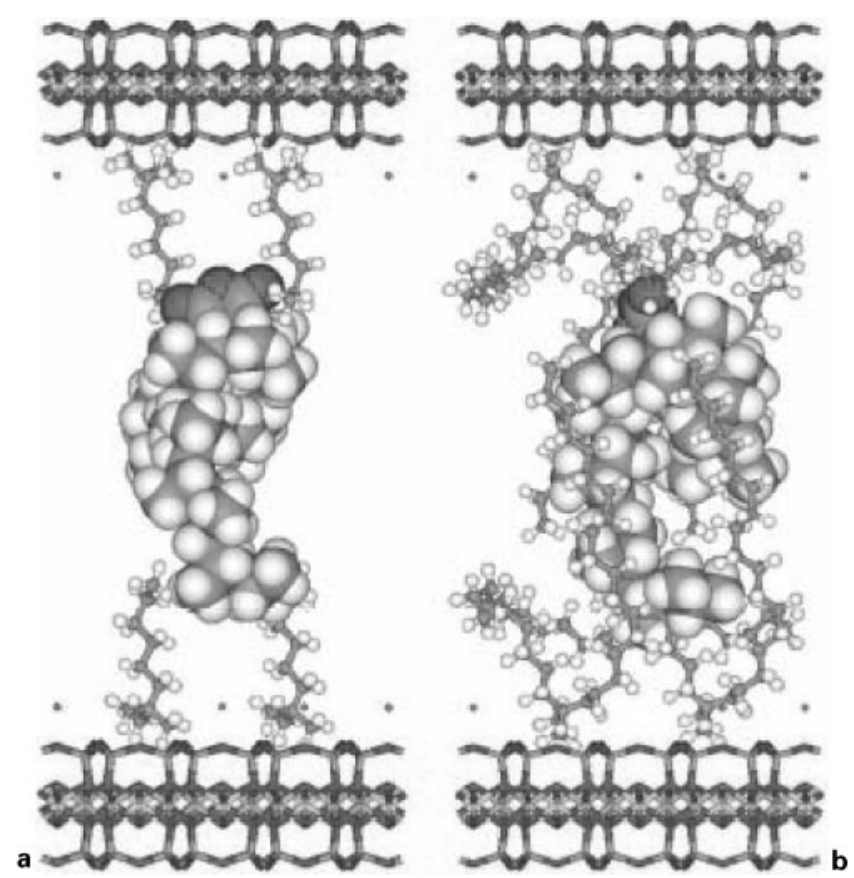

38 Three component model used for basal spacing simulations, consisting of two layers of MMT with $\mathrm{K}^{+}$cations (stick model), $a$ four molecules of trimethylammonium cation or $b$ dimethylstearylammonium cation (stick and ball model), and one molecule of PP-MA (ball model). Reprinted with permission from Ref. 96, ๑ 2004, Elsevier Science 


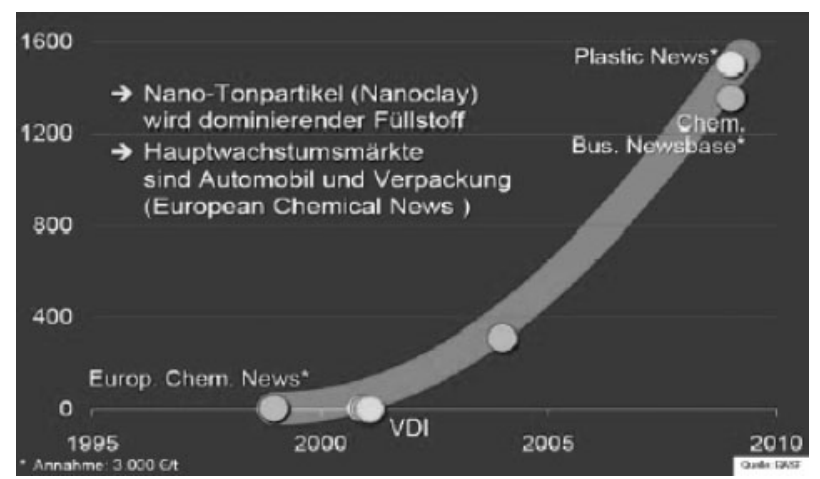

40 Market forecasts (turnover in million Euro) for polymer nanocomposites by various sources: through courtesy of Ebenau ${ }^{101}$

PLSNCs offer attractive potential for diversification and application of conventional polymeric materials. Some of PLSNCs are already commercially available and applied in industrial products.

Biodegradable polymers based nanocomposites have a great deal of future promise for potential applications as high performance biodegradable materials. These are entirely new types of materials based on plant and nature materials (organoclay). When disposed of in compost, these are safely decomposed into $\mathrm{CO}_{2}$, water and humus through the activity of micro-organisms. The $\mathrm{CO}_{2}$ and water will become corn or sugarcane again through plant photosynthesis. Undoubtedly, these unique properties originating from the controlled nanostructure pave the way for much broader range of applications (already commercially available through Unitika Ltd, Japan), and open a new dimension for plastics and composites.

According to several sources (Chemical Business Newsbase, Plastic News), a significant increase in turnover of $\sim 100 \%$ per year leading to a value of $\sim 1500$ million Euro $(\sim 500000 \mathrm{t} /$ year of polymer nanocomposites) is expected (see Fig. 40) in 2009. ${ }^{101}$ Even though these numbers may be overoptimistic, they highlight the tremendous technological and economical potential associated with polymeric nanocomposites including not only clay but also other inorganic nanofillers, such as carbon nanotubes and $\mathrm{SiO}_{2}, \mathrm{SiC}$ and $\mathrm{Si}_{3} \mathrm{~N}_{4}$. At present, it is difficult to predict which, if any, market sector would not be able to benefit from this technology. Therefore, it may well be that polymeric nanocomposites in the mid and long term will pervade all aspects of life, similar to the way plastics did in the last century. Clearly a diverse range of sectors such as aerospace, automotive, packaging (particularely food but also solar cells), electrical and electronic goods, household goods, etc. will profit substantially from a new range of materials which would be offered by this technology.

\section{References}

1. H. Cox, T. Dearlove, W. Rodges and M. Verbrugge: Proc. 4th World Cong. Nanocomposites 2004, San Francisco, CA, September 2004, Executives Conference Management Inc., Session I-(1).

2. M. Okamoto: 'Polymer/layered silicate nanocomposites', Rapra review report No. 163, Rapra Technology, London, 2003.

3. A. Usuki, Y. Kojima, A. Okada, Y. Fukushima, T. Kurauchi and O. Kamigaito: J. Mater. Res., 1993, 8, 1174.
4. National Lead: US patent 2531396, 1950.

5. Union Oil: US patent 3084117, 1963.

6. Unitika: Japanese Kokai patent application 109998, 1976.

7. Y. Fukushima and S. Inagaki: J. Inclus. Phenom., 1987, 5, 473.

8. Y. Kojima, A. Usuki, M. Kawasumi, A. Okada, Y. Fukushima, T. Karauchi and O. Kamigaito: J. Mater. Res., 1993, 8, 1185.

9. M. Jose-Yacaman, L. Rendon and J. Arenas and M. C. S. Puche: Science, 1996, 273, 223.

10. M. C. Hermosin and J. Cornejo: Clay. Clay Miner., 1986, 34, 591.

11. R. Krishnamoorti, R. A. Vaia and E. P. Giannelis: Chem. Mater., 1996, 8, 1728.

12. S. S. Ray, K. Yamada, M. Okamoto, A. Ogami and K. Ueda: Chem. Mater., 2003, 15, 1456.

13. S. P. Su, D. D. Jiang and C. A. Wilkie: Polym. Degrad. Stabil., 2004, 83, 321.

14. S. P. Su, D. D. Jiang and C. A. Wilkie: Polym. Degrad. Stabil., 2004, 83, 333.

15. P. Y. Vuillaume, K. Glinel, A. M. Jonas and A. Laschewsky: Chem. Mater., 2003, 15, 3625.

16. E. J. Acosta, Y. Deng, G. N. White, J. B. Dixon, K. J. McInnes, S. A. Senseman, A. S. Frantzen and E. E. Simanek: Chem. Mater., 2003, 15, 2903.

17. H. Fischer: Mater. Sci. Eng., 2003, C23, 763.

18. N. Hasegawa, H. Okamoto, M. Kato, A. Usuki and N. Sato: Polymer, 2003, 44, 2933.

19. H. van Olphen: 'An introduction to clay colloid chemistry'; 1977, New York, Wiley.

20. A. S. Zerda, T. C. Caskey and A. Lesser: Macromolecules, 2003, 36, 1603.

21. Q. Zhao and E. T. Samulski: Macromolecules, 2003, 36, 6967.

22. P. Maiti, P. H. Nam, M. Okamoto, T. Kotaka, N. Hasegawa and A. Usuki: Macromolecules, 2002, 35, 2042.

23. P. H. Nam, P. Mait, M. Okamoto, T. Kotaka, N. Hasegawa and A. Usuki: Polymer, 2001, 42, 9633.

24. P. Maiti, P. H. Nam, M. Okamoto, T. Kotaka, N. Hasegawa and A. Usuki: Polym. Eng. Sci., 2002, 42, 1864.

25. R. Khare, J. J. de Pablo and A. Yethiraj: Macromolecules, 1996, 29, 7910 .

26. N. Sheng, M. C. Boyce, D. M. Parks, G. C. Rutledge, J. I. Abes and R. E. Cohen: Polymer, 2004, 45, 487.

27. K. A. Carrado: in 'Handbook of layered materials', (ed. S. M. Auerbach, K. A. Carrado and P. K. Dutta), 1-38; 2004, New York, Marcel-Dekker.

28. H. Sato, A. Yamagishi and K. Kawamura: J. Phys. Chem. B, 2001, B105, 7990.

29. Y.-S. Seo, Y. Ichikawa and K. Kawamura: Mater. Sci. Res. Int., 1999, 5, 13

30. K. Tamura, H. Setsuda, M. Taniguchi and A. Yamagishi: Langmuir, 1999, 15, 6915.

31. F. J. Medellin-Rodriguez, C. Burger, B. S. Hsiao, B. Chu, R. A. Vaia and S. Phillips: Polymer, 2001, 42, 9015.

32. P. Maiti and M. Okamoto: Macromol. Mater. Eng., 2003, 288, 440.

33. W. J. Landis: Connect. Tissue Res., 1996, 35, 1.

34. D. M. Lincoln, R. A. Vaia, Z. G. Wang and B. S. Hsiao: Polymer, 2001, 42, 1621 .

35. D. M. Lincoln and R. A. Vaia: Macromolecules, 2004, 37, 4554.

36. G. M. Kim, D. H. Lee, B. Hoffmann, J. Kressler and G. Stoppelmann: Polymer, 2001, 42, 1095.

37. T. Stern, E. Wachtel and G. Marom: J. Polym. Sci. B, 1997, 35B, 2429.

38. P. Fratzl, H. S. Gupta, E. P. Paschalis and P. Roschger: J. Mater. Chem., 2004, 14, 2115.

39. L. Priya and J. P. Jog: J. Polym. Sci. B, 2002, 40B, 1682.

40. D. Shah, P. Maiti, E. Gunn, D. F. Schmidt, D. D. Jiang, C. A. Batt and E. P. Giannelis: Adv. Mater., 2004, 16, 1173.

41. S. S. Ray, K. Yamada, M. Okamoto and K. Ueda: Polymer, 2003, 44, 857.

42. J. S. Chen, M. D. Poliks, C. K. Ober, Y. Zhang, U. Wiesner and E. P. Giannelis: Polymer, 2002, 43, 4895.

43. S. S. Ray, K. Okamoto and M. Okamoto: Macromolecules, 2003, 36, 2355.

44. K. Okamoto, S. S. Ray and M. Okamoto: J. Polym. Sci. B, 2003, 41B, 3160.

45. L. A. Utracki: 'Polymer alloys and blends: thermodynamics and rheology'; 1990, New York, Hasser.

46. W. P. Cox and E. H. Merz: J. Polym. Sci., 1958, 28, 619.

47. M. Okamoto, H. Sato, H. Taguchi and T. Kotaka: J. Soc. Rheol., 2000, 28, 201. 
48. M. Okamoto, P. H. Nam, P. Maiti, T. Kotaka, N. Hasegawa and A. Usuki: Nano Lett., 2001, 1, 295.

49. T. Kotaka, A. Kojima and M. Okamoto: Rheol. Acta, 1997, 36, 646.

50. P. H. Nam: 'The structure and properties of intercalated PP/clay nanocomposites', Master dissertation, Toyota Technological Institute, 2001.

51. Y. Kojima, A. Usuki, M. Kawasumi, A. Okada, T. Kurauchi, O. Kamigaito and K. Kaji: J. Polym. Sci. B, 1995, 33B, 1039.

52. B. Yalcin and M. Cakmak: Polymer, 2004, 45, 2691.

53. F. J. Medellin-Rodriguez, C. Burger, B. S. Hsiao, B. Chu, R. A. Vaia and S. Phillips: Polymer, 2001, 42, 9015.

54. A. Lele, M. Mackley, G. Galgali and C. Ramesh: J. Rheol., 2002, 46, 1091.

55. A. Bafna, G. Beaucage, F. Mirabella and S. Mehta: Polymer, 2003, 44, 1103

56. R. Roe: 'Methods of X-ray and neutron scattering in polymer science', 199; 2000, New York, Oxford University Press.

57. A. Bafna, G. Beaucage, F. Mirabella, G. Skillas and S. Sukumaran: J. Polym. Sci. B, 2001, 39B, 2923.

58. J. W. Kim, S. G. Kim, H. J. Choi and M. S. Jhon: Macromol. Rapid Commun., 1999, 20, 450.

59. J. W. Kim, M. H. Noh, H. J. Choi, D. C. Lee and M. S. Jhon: Polymer, 2000, 41, 1229.

60. J. H. Park, Y. T. Lim and O. O. Park: Macromol. Rapid Commun., 2001, 22, 616

61. Y. T. Lim, J. H. Park and O. O. Park: J. Coll. Interf. Sci., 2002, 245, 198.

62. M. Okamoto, P. H. Nam, M. Maiti, T. Kotaka, T. Nakayama, M. Takada, M. Ohshima, A. Usuki, N. Hasegawa and H. Okamoto: Nano Lett., 2001, 1, 503.

63. P. Fratzl: Curr. Opin. Colloid Interf. Sci., 2003, 8, 32.

64. P. H. Nam, M. Okamoto, P. Maiti, T. Kotaka, T. Nakayama, M. Takada, M. Ohshima, N. Hasegawa and A. Usuki: Polym Eng. Sci., 2002, 42, (9), 1907.

65. M. Mitsunaga, Y. Ito, M. Okamoto, S. S. Ray and K. Hironaka: Macromol. Mater. Eng., 2003, 288, 543.

66. D. Klempner and K. C. Frisch: 'Handbook of polymeric foams and foam technology'; 1991, Munich, Vienna, Hanser.

67. J. S. Colton and N. P. Suh: Polym. Eng. Sci., 1987, 27, 485.

68. Y. Ito and M. Okamoto: Macromolecular Mater. Eng., to be published.

69. Y. Fujimoto, S. S. Ray, M. Okamoto, A. Ogami and K. Ueda: Macromol. Rapid Commun., 2003, 24, 457.

70. X. Cao, L. J. Lee, T. Widya and C. Macosko: Polymer, 2005, 46 775

71. A. Chandra, S. Gong, L. S. Turng, P. Gramann and H. Cordes: Polym. Eng. Sci., 2005, 45, 52.

72. K. Taki, T. Yanagimoto, E. Funami, M. Okamoto and M. Ohshima: Polym. Eng. Sci., 2004, 44, 1004.

73. W. Strauss and N. A. D'Souza: J. Cell. Plast., 2004, 40, 229.

74. H. Fong, W. Liu, C. S. Wang and R. A. Vaia: Polymer, 2002, 43, 775 .
75. J. M. Brown, D. B. Curliss and R. A. Vaia: Proc. 219th ACS Natl Meet., San Francisco, CA, March 2000, American Chemical Society, 278

76. S. S. Ray, K. Okamoto, K. Yamada and M. Okamoto: Nano Lett., 2002, 2, 423.

77. L. J. Gibson and M. F. Ashby (eds.): 'Cellular solids', 8; 1988, New York, Pergamon Press.

78. J. A. Tetto, D. M. Steeves E. A. Welsh and B. E. Powell: Proc. Ann. Tech. Conf., May 1999, Society of Plastics Engineers, 1628.

79. S. R. Lee, H. M. Park, H. L. Lim T. Kang, X. Li, W. J. Cho and C. S. Ha: Polymer, 2002, 43, 2495.

80. S. S. Ray, M. Okamoto, K. Yamada and K. Ueda: Nano Lett., 2002, 2, 1093.

81. S. S. Ray, K. Yamda, A. Ogami, M. Okamoto and K. Ueda: Macromol. Rapid Commun., 2002, 23, 943.

82. S. S. Ray, K. Yamada, M. Okamoto and K. Ueda: Macromol. Mater. Eng., 2003, 288, 936.

83. S. S. Ray, K. Yamada, M. Okamoto and K. Ueda: Polymer, 2003, 44, 857.

84. J. W. Liu, Q. Zhao and C. X. Wan: Space Med. Med. Eng., 2001, 14, 308.

85. K. Okamoto, S. S. Ray and M. Okamoto: J. Polym. Sci. B, 2003, 41B, 3160.

86. R. Hiroi, S. S. Ray, M. Okamoto and T. Shiroi: Macromol. Rapid. Commun., 2004, 25, 1359

87. A. Fujishima and K. Honda: Nature, 1972, 37, 238.

88. R. Simha, L. A. Utracki and A. Garcia-Rejon: Compos. Interf., $2001,8,345$

89. S. Tanoue, L. A. Utracki, A. Garcia-Rejon, J. Tatibouet, K. C. Cole and M. R. Kamal: Polym. Eng. Sci., 2004, 44, 1046

90. L. A. Utracki and R. Simha: Macromolecules, 2004, 37, 10123.

91. Y. Wang, Y. Wu, H. zhang, L. Zhang, B. Wang and Z. Wang: Macromol. Rapid Commun., 2004, 25, 1973.

92. V. V. Ginzburg and A. C. Balazs: Macromolecules, 1999, 32, 5681.

93. V. V. Ginzburg, C. Singh and A. C. Balazs: Macromolecules, 2000, 33, 1089

94. V. V. Ginzburg and A. C. Balazs: Adv. Mater., 2000, 12, 1805.

95. V. V. Ginzburg, O. V. Gendelman and L. I. Manevitch: Phys. Rev. Lett., 2001, 86, 5073 .

96. R. Totha, A. Coslanicha, M. Ferronea, M. Fermeglia, S. Pricl, S. Miertus and E. Chiellini: Polymer, 2004, 45, 8075.

97. A. Sinsawat, K. L. Anderson, R. A. Vaia and B. L. Farmer: J. Polym. Sci. Part B: Polym. Phys., 2003, 41, 3272.

98. V. Kuppa, S. Menakanit, R. Krishnamoorti and E. Manias: J. Polym. Sci B, 2003, 41B, 3285 .

99. Q. H. Zeng, A. B. Yu, G. Q. Lu and R. K. Standish: Chem. Mater., 2003, 15, 4732.

100. N. Sheng, M. C. Boyce, D. M. Parks, G. C. Rutledge, J. I. Abes and R. E. Cohen: Polymer, 2004, 45, 487.

101. A. Ebenau: 'Wirtschaftliche perspektiven der nanotechnologie: enorme markte fur kleinste teilchen'; 2002, Mannheim, BASF Future Business GmbH. 